\title{
OPTIMAL STRATEGIES FOR A CAPITAL CONSTRAINED CONTRACT-FARMING SUPPLY CHAIN WITH YIELD INSURANCE
}

\author{
Ligang Shi ${ }^{1}$, TaO PAng ${ }^{2}$ And Honguun Peng ${ }^{1, *}$
}

\begin{abstract}
We consider a capital-constrained contract-farming supply chain with a risk-averse farmer and a risk-neutral agro-dealer, where the farmer faces some yield uncertainty that can be covered by insurance. Using the Stackelberg model, we derive the optimal strategies on the insured level, production and wholesale price. The result shows that farmers with low risk aversion tend not to be insured, while those with high risk aversion tend to insure. Further analysis indicates that, as the degree of the farmer's risk aversion increases, the farm size decreases, but the yield per unit area and the wholesale price of the agricultural product increases. In addition, yield insurance and premium subsidies can lead to a decrease of the yield per unit area. However, the expansion of the farm size can compensate for the inhibitory effect of the decrease of yield per unit area on the total yield, and thus the total yield increases. We also find that when the premium subsidy rate is low, the yield insurance's value to farmers is negative. Moreover, the yield insurance's value to farmers increases with respect to the bank's interest rate.
\end{abstract}

Mathematics Subject Classification. 90B10, 91A80.

Received June 1, 2020. Accepted January 15, 2021.

\section{INTRODUCTION}

Due to unpredictable conditions such as weather, pests and diseases, there are some yield uncertainties in the agricultural production. Between 2005 and 2015, approximately USD 96 billion was lost as a result of declines in crop and livestock production in developing countries following natural disasters [22]. In addition, agriculture in developing countries is predominantly a smallholder economy, and the frequent occurrence of natural disasters poses a great challenge to farmers' production activities [5]. A very effective solution to mitigate the farmers' losses due to natural disasters is agricultural insurance. Actually, many countries and regions actively explore policy-based agricultural yield insurance systems [16]. Under the yield insurance, when the actual crop yield falls below a certain threshold yield level, the insurance institution compensates the farmers up to the certain yield level. Therefore, the insurance can protect the farmers' expected income up to a certain level.

In recent years, contract farming has become increasingly popular in many countries [23]. More than $60 \%$ of large farms in the United States have used contracts, covering roughly $40 \%$ of the annual value of agricultural products. Although contract farming emerged late in China, it has been widely promoted and becomes more and

Keywords. Contract-farming, yield uncertainty, yield insurance, capital constraint, risk-averse.

1 College of Economics and Management, Nanjing Forestry University, Nanjing 210037, P.R. China.

2 Department of Mathematics, North Carolina State University, Raleigh, NC 27695-8205, USA.

*Corresponding author: penghj@njfu.edu.cn 


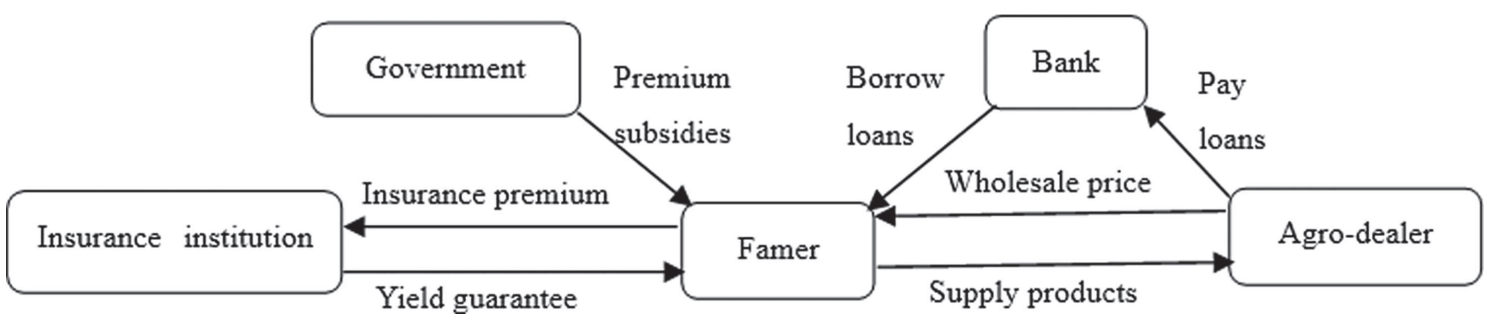

FigURE 1. Framework of contract-farming supply chain financial system with insurance.

more popular since the 1990s. The emergence of contract farming provides a stable sales channel for agricultural products, so the contract farmers have the motivation to expand the farm size [28], and then have increasing demands for financial resources [13,20]. However, due to the long production cycle of agriculture and the threat of yield uncertainty, farmers always face financing difficulties [26]. In 2016, the rural financial deficit in China has reached CNY 3 trillion, and less than $20 \%$ of the farmers get loans from financial institutions [34].

Despite of the contract farming popularity, there are still many open questions to be answered. For example, how does financing rate affect the decision of the contract-farming supply chain? Can yield insurance and premium subsidies encourage farmers to expand farm size and promote yield per unit area of agricultural products? Can premium subsidies encourage farmers to attend yield insurance? We aim at finding the answers for those questions.

We consider a contract-farming supply chain with a risk-averse farmer and a risk-neutral agro-dealer (see Fig. 1). The farmer faces some yield uncertainty and capital constraint, and the market price of agricultural products is also uncertain. The farmer needs to apply for bank loans before the production season. In order to reduce the risk of yield uncertainty, the farmer can purchase the yield uncertainty insurance. The government can encourage farmers to purchase the insurance by providing premium subsidies. If farmers purchase yield insurance from the insurance company, they need to decide the level of yield guarantee. As a result, if the yield turns out to be lower that the guaranteed level, the insurance company will pay compensation according to the insurance policy. We will analyze the impacts on premium subsidies, financing rate, the risk-averse degree and yield uncertainty on the optimal decisions and profits of the contract-farming supply chain, and discuss the value of yield insurance to farmers.

The rest of the paper is organized as follows. In Section 2, we review the relevant literature and summarize the differences between this paper and current literature. We provide details of our model in Section 3. In Section 4, we characterize the equilibrium decisions of the contract-farming supply chain under the yield insurance mechanism. In Section 5, we give some discussions and provide some managerial insights. We conclude the paper and suggest some possible extensions in Section 6 .

\section{LiterATURE REVIEW AND MOTIVATIONS}

In this section, we review some literature on agricultural insurance, supply chain finance and agricultural supply chain management, respectively.

\subsection{Agricultural insurance}

Some researchers concern farmers' willingness to participate in the insurance. Ahmad et al. [2] analyze the effect of farmers' risk attitude and risk perception on the decision of the agricultural insurance sector by investigating 402 wheat-producing farmers in Punjab, Pakistan. Based on a survey of farmers in Heilongjiang Province, China, Liu et al. [31] find that farmers from flooded areas have a higher willingness to pay for index insurance than those from non-flooded areas. 
In addition, the impact of agricultural insurance has received many attentions. Cai [8] uses a natural experiment to analyze the impact of agricultural insurance. The result shows that attending insurance increases the crop production and the credit demand of farmers, but has no effect on household savings. Through an experiment of smallholder farmers in Bangladesh, Hill et al. [29] find that agricultural insurance expands the farm size, which lead to an increase in agricultural input expenditures. However, some authors get the result that agricultural insurance may result in moral hazard and adverse selection of farmers [27,33].

To encourage farmers to attend insurance, governments always carry out premium subsidies policy. Based on the annual crop data of about 180000 counties, Yu et al. [53] show that premium subsidies increase the farm size and expected profits of farmers. Freudenreich et al. [24] demonstrate that premium subsidies can increase the adoption probability of productivity-enhancing technologies through a framed field experiment with Mexican maize farmers. Fadhliani et al. [21] use numerical simulation to analyze the impact of crop insurance policy for risk-averse Indonesian rice farmers. The empirical result shows that higher subsidy rates reduce input use and the expected yield.

The above literature mostly adopts empirical study based on survey data, and the conclusions are often inconsistent. In addition, none of them considers the impact of agricultural insurance and premium subsidies on farmers' financing strategies. To fill this gap, we develop a game model to study the impact of agricultural insurance and premium subsidies on the production, price and financing strategies for the capital-constrained contract-farming supply chain.

\subsection{Supply chain finance}

There are two main modes of supply chain finance: bank credits (external financing) and trade credits (internal financing). Buzacott et al. [7] are the first to introduce asset-based financing into production decision-making and analyze the optimal strategies of the supply chain financing system. Sharma et al. [42] develop a fuzzy inventory model to investigate the impact of credit policy on the optimality of the solution for the non-instantaneous deteriorating products. Yang et al. [49] study the advertising strategies of a capital-constrained retailer. The result shows that the retailer with less initial capital is more likely to invest all of his initial capital in advertising.

Some other literature compares the two financing modes. Chen et al. [10] examine the retailer's financing strategy under uncertain demand. They show that trade credit is better than bank credit for channel members in a wholesale price contract. Zhou et al. [56] show that when retailers are moderately rich, trade credit is better for the retailer only if the bank interest rate is above the threshold. Wu et al. [47] study the financing strategies of the green supply chain. The result shows that only when the manufacturer provides trade credit contract for the retailer, the supply chain can achieve a win-win outcome.

Generally, the above literature mainly focuses on demand uncertainty in capital-constrained supply chain, and few of them consider yield uncertainty. Except that Peng et al. [37] propose an advance payment with risk compensation mechanism (APRC) based on yield uncertainty. The result shows that APRC can bring higher profits to the members of the supply chain when the supplier has less self-capital. However, they do not consider production insurance in the paper. We will fill the gap in this paper.

\subsection{Agricultural supply chain management}

More and more authors consider the design of agricultural supply chain contracts in recent years. Niu et al. [35] analyze cost-sharing contract in the "firm + farmer" model and find that it can achieve a win-win situation for both channel members when the firm's cost-sharing ratio is below a threshold level. Huang et al. [30] propose a moderate order boundary contractual agreement to address the possible decline in quantity and quality of agricultural products during the production process. The result shows that this agreement can achieve a win-win situation for both parties by reducing the risk to the grower. Anderson et al. [4] consider a three-level agricultural supply chain with a fertilizer supplier, a grain grower and a grain buyer and design price compensation contracts to achieve supply chain coordination. 
TABLE 1. Comparison of most related existing literature and this paper.

\begin{tabular}{lllll}
\hline \hline & $\begin{array}{l}\text { Yield } \\
\text { uncertainty }\end{array}$ & $\begin{array}{l}\text { Supply } \\
\text { finance }\end{array}$ & $\begin{array}{l}\text { chain } \\
\text { Risk-averse } \\
\text { decision } \\
\text { maker }\end{array}$ & $\begin{array}{l}\text { Agricultural } \\
\text { insurance }\end{array}$ \\
\hline Niu et al. $[35]$ & & & $\sqrt{ }$ & $\sqrt{ }$ \\
Anderson et al. $[4]$ & & & $\sqrt{ }$ & \\
Ye et al. $[51]$ & $\sqrt{ }$ & $\sqrt{ }$ & $\sqrt{ }$ \\
Peng et al. $[38]$ & $\sqrt{ }$ & & $\sqrt{ }$ & $\sqrt{ }$ \\
Fu et al. $[25]$ & $\sqrt{ }$ & & $\sqrt{ }$ & $\sqrt{ }$ \\
Wang et al. $[46]$ & $\sqrt{ }$ & $\sqrt{ }$ & $\sqrt{ }$ & $\sqrt{ }$ \\
Yu et al. $[52]$ & $\sqrt{ }$ & $\sqrt{ }$ & & \\
This paper & $\sqrt{ }$ & & &
\end{tabular}

Some literature also examines production and pricing decisions in the agricultural supply chain. Ye et al. [50] study optimal production, price and financing strategies for the farmer who faces yield uncertainty. Considering yield uncertainty, Peng et al. [38] study the optimal strategies for the three-level contract-farming supply chain under agricultural subsidy. The result shows that the effect of subsidy on the farmer's profits depends on their level of risk aversion. Yan et al. [48] integrate the fairness concern of the manufacturer into a supply chain of fresh agricultural products and investigate the influence of fairness behavior of the manufacturer on the optimal decision of fresh agricultural products supply chain.

Only a few papers consider agricultural insurance in the agricultural supply chain. Fu et al. [25] design a risk transfer mechanism based on weather index insurance to coordinate the supply chain. Wang et al. [46] analyze the impact of farmers' risk aversion on supply chain decisions and discuss the value of commercial insurance. However, they do not consider the financial constraints and premium subsidies mechanism. Considering agricultural cost insurance, $\mathrm{Yu}$ et al. [52] construct a three-party game model of an agribusiness firm, a retailer and government to study the farm size, the purchase price and the subsidy rate strategies for the agricultural supply chain. However, they do not consider farmers' risk preferences and insurance decision. In fact, farmers are usually risk-averse and need to decide whether to attend insurance. In addition, the existing literature only considers the farmer's production quantity decision. In fact, farmers always need to decide the production scale and the effort level. Therefore, in order to make our research much closer to the actual case, we consider a capital-constrained contract-farming supply chain, where the farmer is risk-averse and faces random yield. We derive the strategies of the farm size, yield per unit area (effort level) and insurance for the farmer under the mechanism of yield insurance and premium subsidies.

\subsection{Motivations and highlights}

Under the mechanism of yield insurance and premium subsidies, we consider the contract-farming supply chain consisting of a risk-averse farmer and a risk-neutral agro-dealer. We aim to analyze how the yield insurance, premium subsidies, the risk averse degree, financing cost and yield uncertainty affect the optimal strategies and profits of the contract-farming supply chain.

Table 1 summarizes the differences of the models considered in this paper and some other existing literature. In short, the main contributions of this paper are as follows. (1) To the best of our knowledge, we are the first to study the strategies of the capital-constrained farmer under yield insurance and premium subsidies. Furthermore, we investigate the value of yield insurance. (2) Instead of only considering the farmer's production quantity decision, we analyze the farmer's optimal strategies of the farm size and yield per unit area (effort level). We also investigate the insured decision of the farmer. (3) We consider the yield uncertainty, the capital constraints and the risk preference of the farmer and show how premium subsidies, financing rate, the risk-averse degree and yield uncertainty affect the decisions and profits of the supply chain. 


\section{Notations AND MODEL SETUP}

We consider a two-level contract-farming supply chain including a risk-averse farmer and a risk-neutral agrodealer, where the farmer faces some yield uncertainty and capital constraints (see Fig. 1). Before the production season, the agro-dealer signs an order contract with the farmer in which the wholesale price of the agricultural products is pre-determined. The farmer then needs to decide whether to buy yield insurance to reduce production uncertainty risk. After signing the contract and deciding whether to buy insurance, the farmer applies for bank loans to cover the capital deficit (if any). At the end of the production season, the agro-dealer acquires all the agricultural products and sells them in the retail market. For convenience, we use subscript $f$ to represent the farmer and subscript $m$ to represent the agro-dealer.

The following is the list for some main variables and parameters, which is followed by more description and model setup.

$X$ : the random yield of agricultural products $(\mathbf{E}[X]=1)$;

$\sigma^{2}$ : the variance of $X\left(\operatorname{Var}(X)=\sigma^{2}\right)$;

$q_{0}$ : the basic yield per unit area of agricultural products;

$q$ : the target yield per unit area of agricultural products, the farmer's decision variable;

$s$ : the farm size of agricultural products, the farmer's decision variable;

$s_{0}$ : the threshold for the farm size;

$Q$ : the total target yield of agricultural products $(Q=s \cdot q)$;

$c_{1}$ : the cost per unit area spending on seeds, feeds, etc;

$c_{2}$ : the cost coefficient representing the efficiency of the farmer's effort to improve the farm size;

$c_{3}$ : the cost coefficient representing the efficiency of the farmer's effort to improve the farm yield;

$w$ : the wholesale price of the agricultural product, the agro-dealer's decision variable;

$p$ : the retail price of the agricultural product;

$a, b$ : The intercept and slope of the anti-demand curve of agricultural products;

$\mu$ : the insured yield guarantee level;

$\lambda$ : the insurance premium per unit area;

$h$ : the premium subsidies rate per unit area;

$\theta$ : the insurance company's relative security loading;

$\zeta$ : the farmer's initial capital;

$\eta$ : the degree of the farmer's risk aversion;

$r$ : the bank's interest rate;

CS: consumer surplus

SW: social welfare

$f(\cdot), F(\cdot)$ : the probability density and cumulative distribution of $X$;

$\pi_{f}, \pi_{m}$ : the profits of the farmer and the agro-dealer, respectively.

We denote the target yield per unit area of the farm by $q$. To describe the yield uncertainty, we assume that the actual yield per unit area is $q X$, where $X$ is a random variable with probability density function $f(x)$ and distribution function $F(x)$. Without loss of generality, we further assume that $\beta$ is the upper bound for $X$, $\mathbf{E}[X]=1$ and $\operatorname{Var}(X)=\sigma^{2}$.

It is well known that agricultural production is not economical in scale $[1,35,38]$. In other words, the marginal basic production cost depends on the farm size $s$. Denote $s_{0}$ as the threshold for the farm size, and assume that when $s \leq s_{0}$, the per unit production cost decreases with respect to the farm size $s$, due to fixed inputs for agricultural equipment, specialized and large-scale operations, and when $s>s_{0}$, the per unit production cost increases with respect to $s$ due to capacity constraints. In addition, the total production cost of the farmer increases as the farm size $s$ increases. Therefore, the basic production cost of the farmer $C_{b}(s)$ and the production 
cost per unit area $\bar{C}_{b}(s)=\frac{C_{b}(s)}{s}$ should satisfy

$$
\frac{\mathrm{d} C_{b}(s)}{\mathrm{d} s}>0 ; \quad \begin{cases}\frac{\mathrm{d} \bar{C}_{b}(s)}{\mathrm{d} s}<0, & s<s_{0} \\ \frac{\mathrm{d} \bar{C}_{b}(s)}{\mathrm{d} s} \geq 0, & s \geq s_{0} .\end{cases}
$$

Based on the above analysis and similar to Peng et al. [38], we assume that the basic production cost is described as

$$
C_{b}(s)=c_{1} s+c_{2}\left(s-s_{0}\right)^{2},
$$

where $c_{1}>0$ represents the cost per unit area spending on seeds and feeds, etc. and $c_{2}>0$ is the coefficient representing the efficiency of the farmer's effort investment. We assume that the value of $c_{2}$ is generally small and satisfies $c_{2}<\frac{c_{1}}{2 s_{0}}$. It is easy to get that $\frac{\mathrm{d} C_{b}(s)}{\mathrm{d} s}=c_{1}+2 c_{2}\left(s-s_{0}\right)$ and $\bar{C}_{b}(s) \equiv c_{1}+\frac{c_{2}\left(s-s_{0}\right)^{2}}{s}$ satisfy the situation given by (3.1).

In addition, under the basic production cost input $C_{b}(s)$, the farmer expects to get the basic yield $s q_{0}$. The farmer can increase the farm yield through more efforts on fertilizing, weed control and pest control, etc. Therefore, we assume that the total production cost function of the farmer is given by

$$
C(s, q)=c_{1} s+c_{2}\left(s-s_{0}\right)^{2}+c_{3}\left(s q-s q_{0}\right)^{2},
$$

where $c_{3}$ is the cost coefficient representing the efficiency of the farmer's efforts to improve the farm yield, and $c_{3}\left(s q-s q_{0}\right)^{2}\left(q \geq q_{0}\right)$ denotes the cost of extra efforts (such as fertilizing, weed control and pest control, etc) by the farmer in order to improve the farm yield. The Production cost functions (3.1) and (3.2) are also supported by some practice survey. For example, based on the survey data of farmers in China and Madagascar, some researchers find that the yield rate and cost-profit rate of agricultural products both show a significant downward trend after the farm size reaches a certain scale [15,32].

There are two markets for agricultural products: the wholesale market and the retail market. In the wholesale market, due to the weak position of the farmer, the wholesale price $w$ of agricultural products is usually determined by the agro-dealer. In the retail market, the retail price $p$ and the total supply are usually negatively correlated, i.e., the higher the supply of a good, the lower its price. In this paper, we assume that all the farmers are homogeneous, so that the total supply is a multiplier of the product amount $s q X$. In particular, we express the relationship between the retail price of agricultural products and the supply quantity through a linear inverse demand function $p=a-b s q X$, where $a$ is the maximum possible retail price for agricultural products and $b$ denotes the sensitivity of retail price to changes in the supply of agricultural products.

The farmer faces some yield uncertainty, which brings risk to the farmer. Here we introduce an insurance that covers some of the loss due to the yield uncertainty. In particular, we assume that the farmer can choose a yield insurance level $\mu$ such that when $X<\mu$, the insurance institution pays compensation $w s q(\mu-X)$ to the farmer. It is easy to verify that the insurance company expects to pay $\int_{0}^{\mu} w s q(\mu-x) f(x) \mathrm{d} x$.

The insurance premium, $\lambda(\mu)$, is an upfront payment made by the farmer to the insurance company. In practice, the agricultural insurance premium is quoted as the sum of three factors [18]: (i) the pure premium, (ii) management fees, and (iii) additional risk premium. The pure premium represents the expected compensation to the farmer, and management fees and risk additional premium accounts for costs that are proportional to the pure premium. Therefore, based on the actuarially fair principle $[14,19,53]$, the yield uncertainty premium per unit area satisfies

$$
\lambda(\mu)=(1+\theta) \int_{0}^{\mu} w q(\mu-x) f(x) \mathrm{d} x .
$$

where $\theta \in[0,1]$ is the relative security loading of the insurance company; $\theta \int_{0}^{\mu} w q(\mu-x) f(x) \mathrm{d} x$ indicates the various expenses that the insurance company bears for the insurance policy, mainly including management fees and additional risk premium. To encourage farmers to purchase the yield uncertainty insurance, the government may offer some premium subsidies with the rate of $h$ per unit area to farmers who purchase the insurance. 
Since the farmer does not have enough initial capital $(\zeta)$ to produce and buy insurance, he needs to get a loan from a bank. We assume that the bank's interest rate $(r)$ is exogenous, which is consistent with reality, as banks usually have uniform lending policies. With the yield insurance, when the yield is lower that the guaranteed level, the farmer can file a claim to get some payment from the insurance company to cover the loss. Therefore, the farmer is not at risk of bankruptcy.

In this study, we assume that the farmer is risk-averse and the goal is to maximize the profit CVaR (defined by (4.2)) by choosing the optimal strategies on the farm size $s$, the target yield $q$ and the insured yield level $\mu$. In addition, we assume that the agro-dealer is risk-neutral and the goal is to maximize the expected profit by choosing the optimal value for the wholesale price $w$.

The problem can be formulated as a Stackelberg game, where the agro-dealer is the leader and the farmer is the follower. First, the agro-dealer chooses the optimal wholesale price $w$ to maximize its expected profit $\pi_{m}$, and then for any given $w$, the farmer decides the farm size $s$, target yield per unit area $q$, and the insured yield level $\mu$ to maximize the profit CVaR. The problem can be solved backward by first figuring out the feedback optimal strategies of the farmer for any give wholesale price $w$, and then deriving the optimal wholesale price $w^{*}$ for the agro-dealer.

\section{Optimal STRATEGIES UNDER THE YIELD UNCERTAINTY INSURANCE}

\subsection{The farmer's optimal strategies}

First we figure out the optimal strategies on farm size $s$, target unit yield $q$, and the insured yield level $\mu$ for the farmer, who is the follower in the game. The farmer's profit is as follows:

$$
\pi_{f}(s, q, \mu)=w s q \max (\mu, X)-(1+r)[C(s, q)+(1-h) \lambda(\mu) s]+r \zeta
$$

where $\lambda(\mu)$ is given by (3.3).

We assume that the farmer is risk-averse, and the farmer considers not only the expected profits, but also the risk of losses caused by yield uncertainty. There are three widely used risk measures in the existing literature on risk aversion characteristics: variance, value-at-risk $(\mathrm{VaR})$ and conditional value-at-risk $(\mathrm{CVaR})$. However, the variance measure in the mean-variance method is determined by gains and losses symmetrically, and it is not suitable for small probability events [11]. In addition, the VaR method can't assess the risk of exceeding a certain loss [41]. Unlike those two risk measures, CVaR can measure the tail loss exceeding VaR, which represents the average level of excess loss, and that is what the decision makers are concerned about [12]. Therefore, we use CVaR as the decision criterion to analyze the risk aversion behavior of the farmer [38,51]. According to the general definition of CVaR [40], the goal of the risk-averse farmer is to maximize:

$$
\operatorname{CVaR}_{1-\eta}\left(\pi_{f}(s, q, \mu)\right)=\max _{v \in R}\left\{v+\frac{1}{1-\eta} \mathbf{E}\left[\min \left(\pi_{f}(s, q, \mu)-v, 0\right)\right]\right\}
$$

where the parameter $\eta \in[0,1)$ reflects the confidence level in the CVaR, and it also reflects the farmer's risk aversion level. A larger $\eta$ means the farmer is more risk-averse. When $\eta=0$, the farmer maximize the expected profit and the risk is not considered in this case.

The optimal strategies of the farmer are given in the following proposition.

Proposition 4.1. Given the wholesale price $w$, the farmer's optimal farm size $s^{*}$, target yield per unit area $q^{*}$ and insured yield level $\mu^{*}$ are given by 


$$
\begin{aligned}
& s^{*}= \begin{cases}s_{0}+\frac{w q_{0} G\left(1-\eta_{0}\right)}{2 c_{2}(1+r)}-\frac{c_{1}}{2 c_{2}}, & \eta_{0} \leq \eta<1 ; \\
s_{0}+\frac{w q_{0} G(1-\eta)}{2 c_{2}(1+r)}-\frac{c_{1}}{2 c_{2}}, & 0<\eta<\eta_{0} ;\end{cases} \\
& q^{*}= \begin{cases}q_{0}+\frac{w G\left(1-\eta_{0}\right)}{2 c_{3}\left(1+r s^{*},\right.}, & \eta_{0} \leq \eta<1 ; \\
q_{0}+\frac{w G(1-\eta)}{2 c_{3}(1+r) s^{*}}, & 0<\eta<\eta_{0} ;\end{cases} \\
& \mu^{*}= \begin{cases}F^{-1}\left(1-\eta_{0}\right), & \eta_{0} \leq \eta<1 ; \\
0, & 0<\eta<\eta_{0} ;\end{cases}
\end{aligned}
$$

where

$$
\begin{aligned}
G(y) & =F^{-1}(y)-\frac{1}{y} \int_{0}^{F^{-1}(y)} F(x) \mathrm{d} x \\
\eta_{0} & =1-\frac{1}{(1+r)(1-h)(1+\theta)} .
\end{aligned}
$$

(The proof of Prop. 4.1 is given in Appendix A.1.)

In the above proposition, $\eta_{0}$ represents the threshold of the farmer's risk aversion. If $\eta \geq \eta_{0}$, the farmer chooses to purchase the insurance. Otherwise, the farmer will not purchase the insurance.

From (4.3) and (4.5), we can see that whether the farmer purchases the insurance depends on the farmer's risk aversion level $\eta$, the bank's interest rate $r$, the insurance company's relative security loading $\theta$ and the premium subsidy rate $h$. When the degree of the farmer's risk aversion is high (or the interest rate is low, or the premium subsidy rate is high, or the relative security loading is low), the farmer will choose to insure; otherwise, the farmer will not purchase the insurance. We can also see that once the farmer chooses to get the insurance, the optimal production $q^{*}$ will be independent of the farmer's risk aversion level $\eta$. However, it will be affected by the interest rate $r$, the relative security loading $\theta$ and the insurance premium subsidy rate $h$ (see Eq. (4.5)).

In addition, we also can get the following proposition, which describes the effects of the wholesale price $w$ on the farmer's optimal farm size $s^{*}$ and the optimal total target production $Q^{*}\left(=s^{*} \cdot q^{*}\right)$.

\section{Proposition 4.2.}

$$
\frac{\mathrm{d} s^{*}}{\mathrm{~d} w}>0, \quad \frac{\mathrm{d} Q^{*}}{\mathrm{~d} w}>0
$$

(The proof of Prop. 4.2 is given in Appendix A.2.)

Proposition 4.2 is consistent with intuitions that the agricultural farm size and the target total yield should increase with respect to the wholesale price.

\subsection{The agro-dealer's optimal strategy under the yield insurance}

Since the retail price of agricultural products satisfies $p=a-b s q X$, and $\mathbf{E}[X]=1, \operatorname{Var}(X)=\sigma^{2}$, the agro-dealer's expected profit is given by

$$
\pi_{m}(w)=\mathbf{E}[(a-b s q X) s q X-w s q X]=(a-w) s q-b s^{2} q^{2}\left(1+\sigma^{2}\right) .
$$

We assume that the agro-dealer is risk-neutral, and the goal is to choose the optimal wholesale price $w^{*}$ to maximize the expected profit. According to the backward induction, the agro-dealer chooses the optimal wholesale price $w^{*}$ based on the assumption that, for any given $w$, the farmer chooses the optimal farm size $s^{*}$, target yield per unit area $q^{*}$ and insured yield level $\mu^{*}$ given by (4.3). Therefore, the agro-dealer's decision model is

$$
\max _{w}\left\{\pi_{m}(w)\right\}, \quad \text { subject to } \quad(4.3) .
$$

We have the following results. 
Proposition 4.3. The agro-dealer's optimal strategy is given by

$$
w^{*}=a-s^{*} q^{*}\left[\frac{1}{B}+2 b\left(1+\sigma^{2}\right)\right],
$$

where

$$
B= \begin{cases}\frac{\left(c_{2}+c_{3} q_{0}^{2}\right) G\left(1-\eta_{0}\right)}{2 c_{2} c_{3}(1+r)}, & \eta_{0} \leq \eta<1, \\ \frac{\left(c_{2}+c_{3} q_{0}^{2}\right) G(1-\eta)}{2 c_{2} c_{3}(1+r)}, & 0<\eta<\eta_{0} .\end{cases}
$$

(The proof of Prop. 4.3 is given in Appendix A.3.)

\subsection{The Nash's equilibrium solution}

Now we give the optimal strategies for the supply chain under the Nash's equilibrium. Plugging (4.8) into (4.3), we can get the following theorem:

Theorem 4.4. In the Nash's equilibrium, the optimal farm size $s^{*}$, target yield per unit area $q^{*}$ and wholesale price $w^{*}$ under the yield uncertainty insurance are given by

$$
\left\{\begin{array}{l}
s^{*}=s_{0}+\frac{2 c_{2} c_{3} B a q_{0}-c_{1} c_{3} q_{0}^{2}-2 c_{1} c_{2}\left[1+B b\left(1+\sigma^{2}\right)\right]}{4 c_{2}\left(c_{2}+c_{3} q_{0}^{2}\right)\left[1+B b\left(1+\sigma^{2}\right)\right]} \\
q^{*}=q_{0}+\frac{2 c_{2}^{2} B a+c_{1} c_{2} q_{0}\left[1+2 B b\left(1+\sigma^{2}\right)\right]}{2 c_{2} c_{3} B a q_{0}-c_{1}\left(c_{3} q_{0}^{2}+2 c_{2}\left[1+B b\left(1+\sigma^{2}\right)\right]\right.}, \\
w^{*}=\frac{2 a c_{2}+c_{1} q_{0} b\left(1+\sigma^{2}\right)}{4 c_{2}\left[1+B b\left(1+\sigma^{2}\right)\right]}+\frac{c_{1} q_{0}}{4 c_{2} B} .
\end{array}\right.
$$

In addition, the optimal insured yield level $\mu^{*}$ is given by (4.3).

In the above derivation, if we let $\mu=0$, we can get the optimal strategies without the yield uncertainty insurance. For comparison purpose, we also give the optimal strategies here.

Theorem 4.5. If the yield uncertainty insurance is not available, then the optimal farm size $s^{N *}$, target yield per unit area $q^{N *}$ and wholesale price $w^{N *}$ at the Nash's equilibrium are given by

$$
\left\{\begin{array}{l}
s^{N *}=s_{0}+\frac{2 c_{2} c_{3} B_{1} a q_{0}-c_{1} c_{3} q_{0}^{2}-2 c_{1} c_{2}\left[1+B_{1} b\left(1+\sigma^{2}\right)\right]}{4 c_{2}\left(c_{2}+c_{3} q_{0}^{2}\right)\left[1+B_{1} b\left(1+\sigma^{2}\right)\right]} \\
q^{N *}=q_{0}+\frac{2 c_{2}^{2} B_{1} a+c_{1} c_{2} q_{0}\left[1+2 B_{1} b\left(1+\sigma^{2}\right)\right]}{2 c_{2} c_{3} B_{1} a q_{0}-c_{1}\left(c_{3} q_{0}^{2}+2 c_{2}\left[1+B_{1} b\left(1+\sigma^{2}\right)\right]\right.} \\
w^{N *}=\frac{2 a c_{2}+c_{1} q_{0} b\left(1+\sigma^{2}\right)}{4 c_{2}\left[1+B_{1} b\left(1+\sigma^{2}\right)\right]}+\frac{c_{1} q_{0}}{4 c_{2} B_{1}}
\end{array}\right.
$$

where

$$
B_{1}=\frac{\left(c_{2}+c_{3} q_{0}^{2}\right) G(1-\eta)}{2 c_{2} c_{3}(1+r)}
$$

\section{Discussions AND NUMERICAL ILlustrations}

In this section, we first discuss how the premium subsidy rate $h$, the interest rate $r$, the relative security loading $\theta$, the farmer's risk averse degree $\eta$ and yield uncertainty level $\sigma^{2}$ affect the optimal decisions and profits of the contract-farming supply chain when the insurance is available. In addition, we also illustrate how the premium subsidy rate affects social welfare when the farmer chooses to insure. We then compare the optimal decisions of the contract-farming supply chain with and without yield uncertainty insurance. Finally, we analyze the value of yield uncertainty insurance.

Based on the data of the 2019 China Rural Statistical Yearbook [17], we set the basic yield per acre $q_{0}=$ $600 \mathrm{~kg} /$ acre and the cost per acre $c_{1}=600 \mathrm{CNY} /$ acre. Other parameters in the contract-farming supply chain 
are set as follows: $a=5 \mathrm{CNY} / \mathrm{kg}, b=0.1 \times 10^{-4}, s_{0}=100$ acre, $c_{2}=1, c_{3}=0.5 \times 10^{-4}$ and $\zeta=30000 \mathrm{CNY}$. We further assume that the yield random variable $X$ is uniformly distributed in the region $[1-\alpha, 1+\alpha][9,38,51]$. Thus the variance of $X$ is $\sigma^{2}=\alpha^{2} / 3$. The study of Canada, the United States and other developed countries shows that the management fees of agricultural insurance accounts for $30 \%-35 \%$ of the pure premium, sometimes even more than $50 \%$, which is much higher than the premium rate of about $20 \%$ for general property insurance $[44,55]$. At the same time, because of the specialty of agricultural risks, the additional risk premium rate is also relatively high. Therefore, we assume that $\theta=0.5$. We also set $\alpha=0.9, \eta=0.6, r=0.1, h=0.1$ unless they are stated otherwise. In this case, we get $\sigma^{2}=0.27$ and $\eta_{0}=0.326$.

In addition, the following lemma will be used in subsequent proofs.

\section{Lemma 5.1.}

$$
\frac{\mathrm{d} B}{\mathrm{~d} r}<0,\left\{\begin{array} { l l } 
{ \frac { \mathrm { d } B } { \mathrm { d } h } > 0 , } & { \eta _ { 0 } \leq \eta < 1 ; } \\
{ \frac { \mathrm { d } B } { \mathrm { d } h } = 0 , } & { 0 < \eta < \eta _ { 0 } ; }
\end{array} \quad \left\{\begin{array} { l l } 
{ \frac { \mathrm { d } B } { \mathrm { d } \theta } < 0 , } & { \eta _ { 0 } \leq \eta < 1 ; } \\
{ \frac { \mathrm { d } B } { \mathrm { d } \theta } = 0 , } & { 0 < \eta < \eta _ { 0 } ; }
\end{array} \quad \left\{\begin{array}{ll}
\frac{\mathrm{d} B}{\mathrm{~d} \eta}=0, & \eta_{0} \leq \eta<1 \\
\frac{\mathrm{d} B}{\mathrm{~d} \eta}<0, & 0<\eta<\eta_{0}
\end{array}\right.\right.\right.
$$

(The proof of Lem. 5.1 is given in Appendix A.4.)

\subsection{The farmer's optimal farm size and target yield}

First we consider the impacts of the yield uncertainty $\sigma^{2}$, the interest rate $r$, the premium subsidy rate $h$, the relative security loading $\theta$ and the farmer's risk averse level $\eta$ on the farmer's optimal strategies of farm size $s^{*}$, target unit yield $q^{*}$, and the total target yield $Q^{*}=s^{*} q^{*}$. We have the following results.

\section{Proposition 5.2.}

$$
\begin{aligned}
& \frac{\mathrm{d} s^{*}}{d \sigma^{2}}<0, \quad \frac{\mathrm{d} q^{*}}{d \sigma^{2}}>0, \quad \frac{\mathrm{d} s^{*}}{\mathrm{~d} r}<0, \quad \frac{\mathrm{d} q^{*}}{\mathrm{~d} r}<0, \quad \frac{\mathrm{d} Q^{*}}{\mathrm{~d} r}<0 ; \\
& \left\{\begin{array} { l l } 
{ \frac { \mathrm { d } s ^ { * } } { \mathrm { d } h } > 0 , } & { \eta _ { 0 } \leq \eta < 1 ; } \\
{ \frac { \mathrm { d } s ^ { * } } { \mathrm { d } h } = 0 , } & { 0 < \eta < \eta _ { 0 } ; }
\end{array} \quad \left\{\begin{array} { l l } 
{ \frac { \mathrm { d } q ^ { * } } { \mathrm { d } h } < 0 , } & { \eta _ { 0 } \leq \eta < 1 ; } \\
{ \frac { \mathrm { d } q ^ { * } } { \mathrm { d } h } = 0 , } & { 0 < \eta < \eta _ { 0 } ; }
\end{array} \quad \left\{\begin{array}{ll}
\frac{\mathrm{d} Q^{*}}{\mathrm{~d} h}>0, & \eta_{0} \leq \eta<1 ; \\
\frac{\mathrm{d} Q^{*}}{\mathrm{~d} h}=0, & 0<\eta<\eta_{0}
\end{array}\right.\right.\right. \\
& \left\{\begin{array} { l l } 
{ \frac { \mathrm { d } s ^ { * } } { \mathrm { d } \theta } < 0 , } & { \eta _ { 0 } \leq \eta < 1 ; } \\
{ \frac { \mathrm { d } s ^ { * } } { \mathrm { d } \theta } = 0 , } & { 0 < \eta < \eta _ { 0 } ; }
\end{array} \quad \left\{\begin{array} { l l } 
{ \frac { \mathrm { d } q ^ { * } } { \mathrm { d } \theta } > 0 , } & { \eta _ { 0 } \leq \eta < 1 ; } \\
{ \frac { \mathrm { d } q ^ { * } } { \mathrm { d } \theta } = 0 , } & { 0 < \eta < \eta _ { 0 } ; }
\end{array} \quad \left\{\begin{array}{ll}
\frac{\mathrm{d} Q^{*}}{\mathrm{~d} \theta}<0, & \eta_{0} \leq \eta<1 ; \\
\frac{\mathrm{d} Q^{*}}{\mathrm{~d} \theta}=0, & 0<\eta<\eta_{0}
\end{array}\right.\right.\right. \\
& \left\{\begin{array} { l l } 
{ \frac { \mathrm { d } s ^ { * } } { \mathrm { d } \eta } = 0 , } & { \eta _ { 0 } \leq \eta < 1 ; } \\
{ \frac { \mathrm { d } s ^ { * } } { \mathrm { d } \eta } < 0 , } & { 0 < \eta < \eta _ { 0 } ; }
\end{array} \quad \left\{\begin{array} { l l } 
{ \frac { \mathrm { d } q ^ { * } } { \mathrm { d } \eta } = 0 , } & { \eta _ { 0 } \leq \eta < 1 ; } \\
{ \frac { \mathrm { d } q ^ { * } } { \mathrm { d } \eta } > 0 , } & { 0 < \eta < \eta _ { 0 } ; }
\end{array} \quad \left\{\begin{array}{ll}
\frac{\mathrm{d} Q^{*}}{\mathrm{~d} \eta}=0, & \eta_{0} \leq \eta<1 ; \\
\frac{\mathrm{d} Q^{*}}{\mathrm{~d} \eta}<0, & 0<\eta<\eta_{0}
\end{array}\right.\right.\right.
\end{aligned}
$$

(The proof of Prop. 5.2 is given in Appendix A.5.)

Proposition 5.2 indicates that no matter whether the farmer is insured or not, the optimal farm size $s^{*}$ decreases with respect to the yield uncertainty (in terms of $\sigma^{2}$ ) and the interest rate $r$. However, the target yield per unit area $q^{*}$ increases with respect to the yield uncertainty (in terms of $\sigma^{2}$ ) and the interest rate $r$.

From Proposition 5.2, we can also see that if the farmer is not insured $\left(0<\eta<\eta_{0}\right)$, the optimal farm size $s^{*}$ and the total target yield $Q^{*}$ decrease with respect to the degree of the farmer's risk aversion $(\eta)$, but the target yield per unit area $q^{*}$ increases with respect to $\eta$.

If the farmer is insured $\left(\eta_{0} \leq \eta<1\right)$, the optimal farm size $s^{*}$ and the total target yield $Q^{*}$ both increase with respect to the premium subsidy rate $h$ and decrease with respect to the insurance company's relative security loading $\theta$. However, the target yield per unit area $q^{*}$ decreases with respect to $h$ and increases with respect to $\theta$.

The managerial insight is that the insurance premium subsidies can effectively promote the farmer to expand the farm size. However, the farmer tends to decrease the effort under the premium subsidy policy, which leads to a decrease in the target yield per unit area. Therefore, to encourage the farmer to achieve larger farm size and higher unit production yield at the same time, subsidies based on other factors such as the unit production yield should be considered in addition to the insurance premium subsidy. 


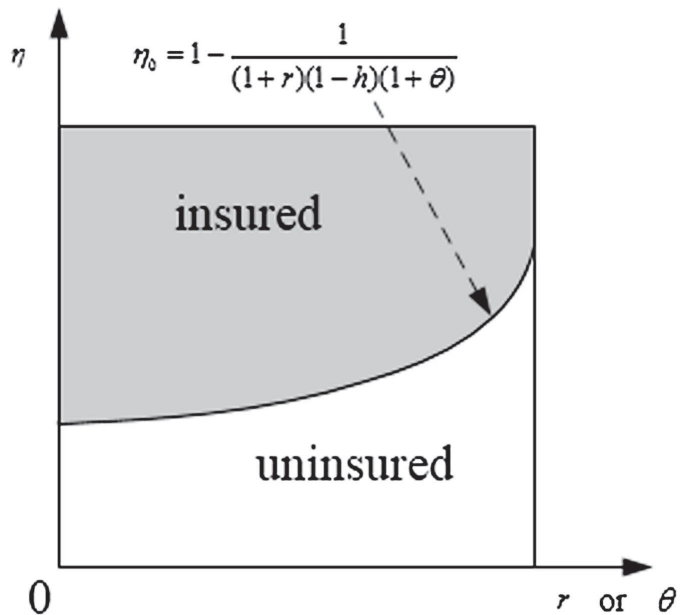

(a)

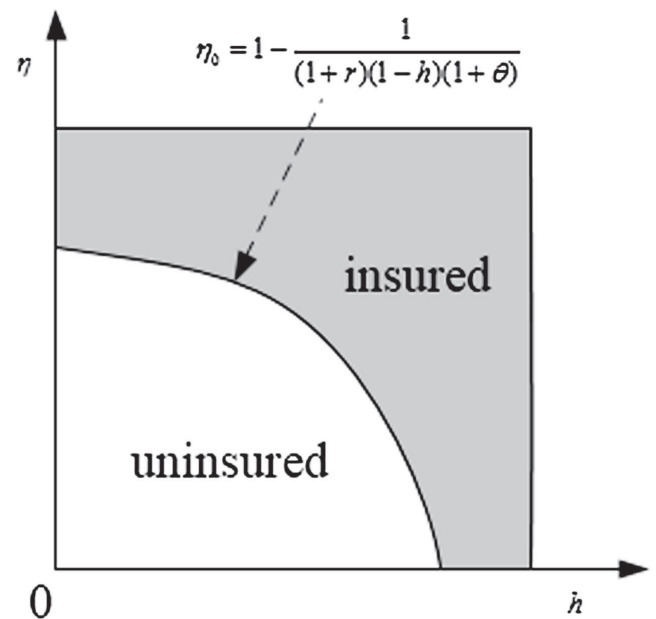

(b)

FIGURE 2. Regional division of whether the farmer is insured or not.

\subsection{The farmer's insurance intention}

Proposition 5.3. The impacts on the farmer's intention to purchase the yield uncertainty insurance are as follows:
(1) $\frac{\mathrm{d} \eta_{0}}{\mathrm{~d} r}>0, \quad \frac{\mathrm{d} \eta_{0}}{\mathrm{~d} h}<0, \quad \frac{\mathrm{d} \eta_{0}}{\mathrm{~d} \theta}>0 ;$
(2) $\quad \frac{\mathrm{d} \mu^{*}}{\mathrm{~d} r}<0, \quad \frac{\mathrm{d} \mu^{*}}{\mathrm{~d} h}>0, \quad \frac{\mathrm{d} \mu^{*}}{\mathrm{~d} \theta}<0, \quad \frac{\mathrm{d} \mu^{*}}{\mathrm{~d} \eta}=0$.

(The proof of Prop. 5.3 is given in Appendix A.6.)

From part (1) of Proposition 5.3, we can see that as the interest rate $r$ decreases or the premium subsidy rate $h$ increases, the threshold of farmers' risk aversion $\eta_{0}$ decreases, which can encourage farmers to purchase the yield uncertainty insurance. Part (1) of Proposition 5.3 is illustrated in Figure 2.

As shown in Figure 2, when the degree of the farmer's risk aversion $\eta$ is higher than or equal to the threshold $\eta_{0}$ (the upper left region in Fig. 2a and the upper right region in Fig. 2b), the farmer chooses to insure. In the other region, the farmer will choose not to insure when $\eta$ is lower than the threshold. Figure 2a shows that the farmer's insured region decreases with the interest rate $r$ and the relative security loading $\theta$. However, Figure 2b shows that the farmer's insured region increases with the premium subsidy rate.

Part (2) of Proposition 5.3 indicates that, because there is no bankruptcy risk under the yield insurance, the farmer's optimal insured yield level $\mu^{*}$ is independent of the farmer's risk aversion level $\eta$. In addition, the insured yield level $\mu^{*}$ decreases with respect to the interest rate $r$ and the relative security loading $\theta$, but increases with respect to the premium subsidy rate $h$.

The managerial insight is that the insurance premium subsidy policy can improve the farmer's insurance desire effectively. Moreover, subsidizing the bank loan interest for the farmer to reduce the financial pressure is also an effective way to improve the farmer's desire for the insurance. 


\subsection{The agro-dealer's wholesale price and expected profits}

Proposition 5.4. The impacts on the agro-dealer's optimal wholesale price and profit are given as follows:

$$
\begin{aligned}
& \text { (1) } \frac{\mathrm{d} w^{*}}{\mathrm{~d} r}>0, \quad \frac{\mathrm{d} \pi_{m}}{\mathrm{~d} r}<0 ; \\
& \text { (2) }\left\{\begin{array} { l l } 
{ \frac { \mathrm { d } w ^ { * } } { \mathrm { d } h } < 0 , } & { \eta _ { 0 } \leq \eta < 1 ; } \\
{ \frac { \mathrm { d } w ^ { * } } { \mathrm { d } h } = 0 , } & { 0 < \eta < \eta _ { 0 } ; }
\end{array} \quad \left\{\begin{array} { l l } 
{ \frac { \mathrm { d } w ^ { * } } { \mathrm { d } \theta } > 0 , } & { \eta _ { 0 } \leq \eta < 1 ; } \\
{ \frac { \mathrm { d } w ^ { * } } { \mathrm { d } \theta } = 0 , } & { 0 < \eta < \eta _ { 0 } ; }
\end{array} \quad \left\{\begin{array}{ll}
\frac{\mathrm{d} w^{*}}{\mathrm{~d} \eta}=0, & \eta_{0} \leq \eta<1 ; \\
\frac{\mathrm{d} w^{*}}{\mathrm{~d} \eta}>0, & 0<\eta<\eta_{0} ;
\end{array}\right.\right.\right. \\
& \text { (3) }\left\{\begin{array} { l l } 
{ \frac { \mathrm { d } \pi _ { m } } { \mathrm { d } h } > 0 , } & { \eta _ { 0 } \leq \eta < 1 ; } \\
{ \frac { \mathrm { d } \pi _ { m } } { \mathrm { d } h } = 0 , } & { 0 < \eta < \eta _ { 0 } ; }
\end{array} \quad \left\{\begin{array} { l l } 
{ \frac { \mathrm { d } \pi _ { m } } { \mathrm { d } \theta } < 0 , } & { \eta _ { 0 } \leq \eta < 1 ; } \\
{ \frac { \mathrm { d } \pi _ { m } } { \mathrm { d } \theta } = 0 , } & { 0 < \eta < \eta _ { 0 } ; }
\end{array} \quad \left\{\begin{array}{ll}
\frac{\mathrm{d} \pi_{m}}{\mathrm{~d} \eta}=0, & \eta_{0} \leq \eta<1 ; \\
\frac{\mathrm{d} \pi_{m}}{\mathrm{~d} \eta}<0, & 0<\eta<\eta_{0} .
\end{array}\right.\right.\right.
\end{aligned}
$$

(The proof of Prop. 5.4 is given in Appendix A.7.)

From the proposition, we can see that the optimal wholesale price $w^{*}$ increases with respect to the interest rate $r$ and the insurance company's relative security loading $\theta$, which most likely decrease the agro-dealer's profit. Similarly, the optimal wholesale price $w^{*}$ increases with respect to the farmer's risk aversion level $\eta$ when the farmer does not purchase insurance $\left(0<\eta<\eta_{0}\right)$, while in this case the agro-dealer's profit $\pi_{m}$ decreases with respect to the farmer's risk aversion level $\eta$. This is because a higher level of risk aversion or interest rate will reduce the farm size, resulting in the reduction of total target yield $Q^{*}$ (see Prop. 5.2). Therefore, the agro-dealer needs to increase the wholesale price in order to encourage farmers to expand the farm size.

Proposition 5.4 also shows that the optimal wholesale price $w^{*}$ decreases with respect to the premium subsidy rate $h$, and it increases the agro-dealer's profit. This is because that, as the premium subsidy rate $h$ increases, the total target yield $Q^{*}$ increases (see Prop. 5.2). Therefore, the agro-dealer does not have to increase the wholesale price to encourage the farmer to increase the production quantity. Instead, the agro-dealer can decrease the wholesale price and the farmer still increases the farm size. As a result, the benefit to the farmer from the premium subsidy is partly offset by the lower wholesale price. The managerial insight is that, while the government provide some premium subsidy to help farmers and intends to protect the farmers' interest, some regulations on the agricultural product wholesale price should be imposed to prevent the agro-dealer from decreasing the wholesale price.

The effects of the yield uncertainty on the optimal wholesale price is not clear. We now performance some numerical studies and the results are shown in Figure 3.

Figure 3a shows that when the farmer does not purchase insurance $\left(0<\eta<\eta_{0}=0.326\right)$, the effect of the yield uncertainty (described by $\sigma^{2}$ ) on the wholesale price $w^{*}$ depends on the farmer's degree of risk aversion $\eta$. Figure 3a indicates that the wholesale price first increases then decreases with respect to $\sigma^{2}$ when the risk aversion is relatively low $(\eta=0.1)$, and the wholesale price increases with $\sigma^{2}$ when the risk aversion is relatively high $(\eta=0.2,0.3)$. This is because that, if the risk aversion and yield uncertainty are relatively high, the production enthusiasm of uninsured farmers is relatively low. In this case, the agro-dealer needs to increase the wholesale price in order to encourage farmers to increase the farm size $s^{*}$. However, when the farmer's risk aversion is relatively low, the farmer is not sensitive to the yield uncertainty. Under this condition, the agro-dealer may decrease the wholesale price $w^{*}$ with a higher yield uncertainty to avoid the risk.

Figure $3 \mathrm{~b}$ shows that when the farmer purchases the yield insurance $\left(\eta_{0} \leq \eta<1\right)$, the effect of yield uncertainty $\sigma^{2}$ on the wholesale price $w^{*}$ depends on the premium subsidy rate $h$. From Figure $3 \mathrm{~b}$, we can get that the wholesale price $w^{*}$ increases with respect to $\sigma^{2}$ when the premium subsidy rate $h$ is relatively low $(h=0.1)$, and decreases with respect to $\sigma^{2}$ when $h$ is relatively high $(h=0.5)$. The reason is that, when the premium subsidy rate is low, the farmer's insurance cost is relatively high and increases with respect to the yield uncertainty. As a result, the production enthusiasm of the farmer decreases. So, the agro-dealer needs to offer a higher wholesale price in order to encourage the farmer to produce more. On the other hand, when the premium subsidy rate is relatively high, the insured farmers can transfer yield uncertainty risk via insurance. Therefore, the farmer can tolerate a relative higher yield uncertainty. In this case, the agro-dealer can decrease the wholesale price without causing the farmer's optimal farm size $s^{*}$ to decrease. 


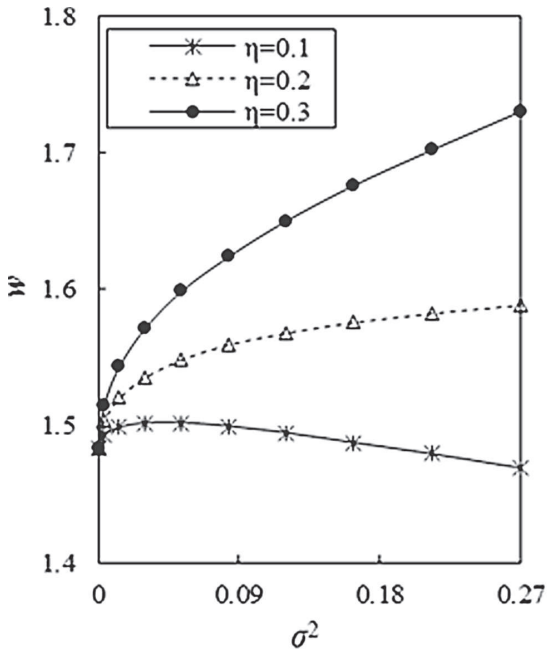

(a)

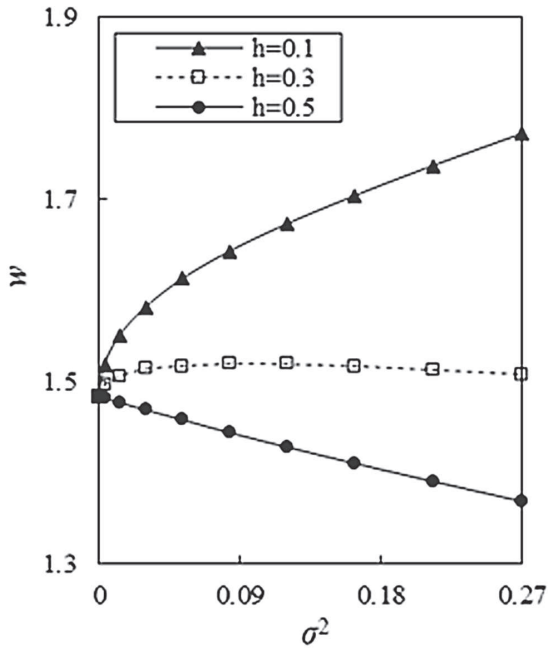

(b)

Figure 3 . The effect of yield volatility variances $\sigma^{2}$ on the wholesale price $w$. (a) $0<\eta<\eta_{0}$.

(b) $\eta_{0} \leq \eta<1$.

\subsection{Social welfare}

The purpose of government subsidies to insured farmers is to maximize the social welfare. Since farmers choose to be insured only when $\eta_{0}<\eta<1$, we discuss the social welfare under this condition.

Based on the concept of social welfare given by Yu et al. [52], we define the social welfare (SW) as the sum of the farmer's expected profit $\pi_{f}$ given by (4.1), the agro-dealer's expected profit $\pi_{m}$ given by (4.6), the consumer surplus CS given by (5.2), and the net government premium expenditure:

$$
\mathrm{SW}=\pi_{f}+\pi_{m}+\mathrm{CS}-h(1+\theta) \int_{0}^{\mu} w s q(\mu-x) f(x) \mathrm{d} x
$$

Consumers' utility is primarily determined by the supply of agricultural products in the market, which also determines the market price of agricultural products (through the formula $p=a-b s q X$ ). More precisely, the consumer surplus can be calculated as the area under the inverse demand curve above the market retail price. Therefore, the consumer surplus function can be obtained as [3]

$$
\mathrm{CS}=E\left[\int_{0}^{s q x}(a-b s q x) \mathrm{d}(s q x)-s q x(a-b s q x)\right]=\frac{1}{2} b s^{2} q^{2}\left(1+\sigma^{2}\right) .
$$

We now use the numerical example to illustrate how the premium subsidy rate affects the social welfare (see Fig. 4). From Figure 4, we can see that social welfare first increases then decreases with respect to the premium subsidy rate $h$ for different yield variance levels $\left(\sigma^{2}=0.03,0.12,0.27\right)$. Therefore, for the numerical example, the premium subsidy rate has a threshold value of $h_{0}\left(h_{0}=0.3\right)$, which maximizes social welfare. The managerial insight is that a premium subsidy rate that is too high may harm the social welfare, and the government should make an optimal decision on the premium subsidy rate $h$, in order to promote active insurance of farmers and to maximize the social welfare. In this numerical example, the optimal premium subsidy rate is $h=30 \%$. 


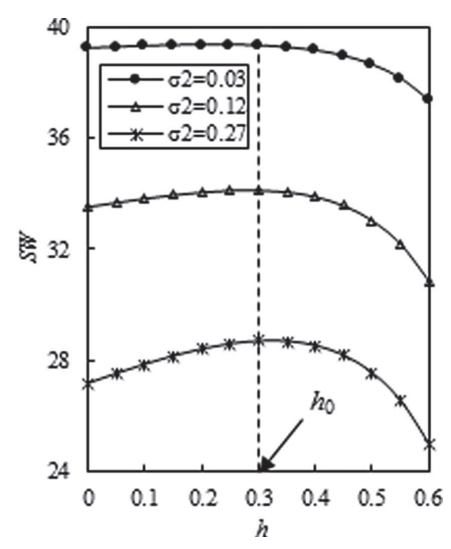

Figure 4 . The effect of the premium subsidy rate $h$ on the social welfare SW.

\subsection{The impacts of yield uncertainty insurance}

\subsubsection{Equilibrium analysis based on insurance coverage}

Now we compare the equilibrium decisions of the contract-farming supply chain with and without insurance. Based on (4.10) and (4.11), we can get the following result.

\section{Proposition 5.5.}

$$
\begin{aligned}
& \left\{\begin{array} { l l } 
{ s ^ { * } > s ^ { N * } , } & { \eta _ { 0 } < \eta < 1 ; } \\
{ s ^ { * } = s ^ { N * } , } & { 0 < \eta \leq \eta _ { 0 } ; }
\end{array} \left\{\begin{array} { l l } 
{ q ^ { * } < q ^ { N * } , } & { \eta _ { 0 } < \eta < 1 ; } \\
{ q ^ { * } = q ^ { N * } , } & { 0 < \eta \leq \eta _ { 0 } ; }
\end{array} \left\{\begin{array}{ll}
w^{*}<w^{N *}, & \eta_{0}<\eta<1 ; \\
w^{*}=w^{N *}, & 0<\eta \leq \eta_{0}
\end{array}\right.\right.\right. \\
& \left\{\begin{array} { l l } 
{ Q ^ { * } > Q ^ { N * } , } & { \eta _ { 0 } < \eta < 1 ; } \\
{ Q ^ { * } = Q ^ { N * } , } & { 0 < \eta \leq \eta _ { 0 } ; }
\end{array} \left\{\begin{array}{ll}
\mathrm{CS}^{*}>\mathrm{CS}^{N *}, & \eta_{0}<\eta<1 \\
\mathrm{CS}^{*}=\mathrm{CS}^{N *}, & 0<\eta \leq \eta_{0} .
\end{array}\right.\right.
\end{aligned}
$$

(The proof of Prop. 5.5 is given in Appendix A.8.)

We also use a numerical example to illustrate the result in Proposition 5.5 and the results are shown in Figure 5. From the figure, we can see that when $\eta \geq \eta_{0}, \eta$ does not affect the optimal strategies of the insured farmer, but it has some impacts on the optimal strategies of the uninsured farmer. As illustrated in Figures 5a and 5d, the optimal farm size $s^{N *}$ and the total target yield $Q^{N *}$ of the uninsured farmer decrease with respect to $\eta$. In addition, the optimal farm size $s^{*}$ and the total target yield $Q^{*}$ of the insured farmer are constants when the degree of the farmer's risk aversion level $\eta$ is higher than the threshold $\left(\eta \geq \eta_{0}\right)$, and they are larger than those of the uninsured farmer. Moreover, according to (5.2), consumers can get more surplus value under the yield insurance.

The existing literature does not have a consistent pattern on whether agricultural insurance will encourage farmers to increase inputs in production materials. Some researchers conclude that insured farmers will choose to reduce the input of chemical fertilizers, pesticides, and agricultural film $[39,45,54]$. On the other hand, some others think that agricultural insurance will encourage farmers to increase the input of pesticides and fertilizers $[6,36]$. Figure $5 \mathrm{~b}$ shows that when the farmer chooses to insure, the yield per unit area of crops is lower than than that without insurance. Therefore, our results are similar to the former conclusion. The reason might be that, under the yield insurance mechanism, the farmer's income at the end of the period is guaranteed. In this case, the farmer may choose to reduce the input of production materials or the effort level, and that usually causes lower yields per unit area. In addition, Figure $5 \mathrm{c}$ show that the wholesale price of the agricultural products $w^{*}$ decrease with respect to $\eta$ if the farmer does not purchase the insurance. For farmers who purchased the yield uncertainty insurance $\left(\eta \geq \eta_{0}\right)$, the wholesale price $w^{*}$ are constants, whose values are less than those of uninsured farmers. 


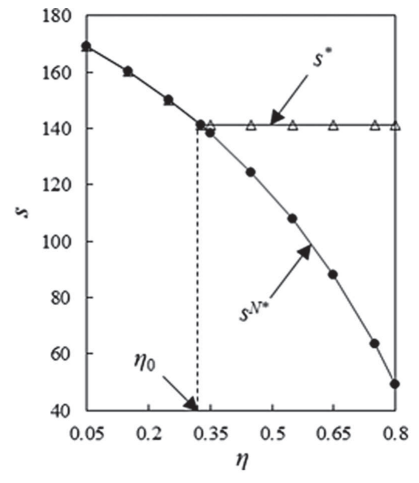

(a)

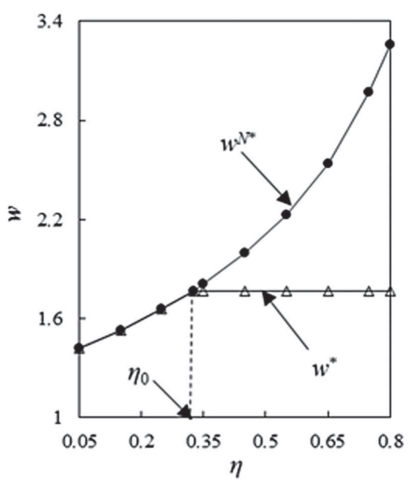

(c)

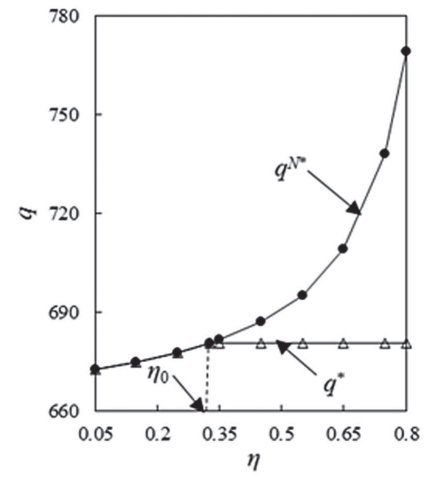

(b)

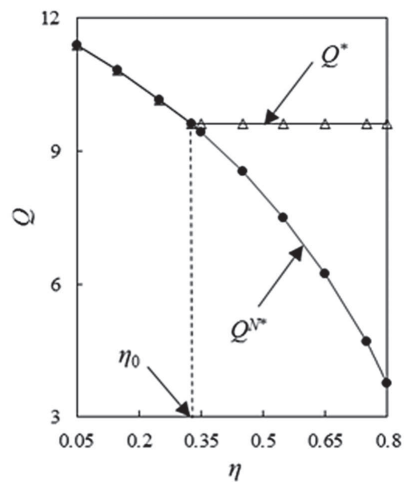

(d)

Figure 5. Comparison of supply chain equilibrium results with and without insurance.

The management insight of Proposition 5.5 is that the government should encourage or subsidize the farmer with high risk aversion level to purchase the yield uncertainty insurance. Moreover, some regulations on the wholesale price should be taken to prevent the agro-dealer from decreasing the wholesale price and some measures such as the subsidy based on the unit yield should be used.

\subsubsection{Value of the yield uncertainty insurance}

In this section, we consider the value of the yield uncertainty insurance to the farmer by considering the relative changes of the farmer's profits with and without insurance. In particular, we define the value of the yield uncertainty insurance as $\triangle \pi_{f} \equiv\left(\pi_{f}^{*}-\pi_{f}^{N *}\right) / \pi_{f}^{N *}$, where $\pi_{f}^{*}, \pi_{f}^{N *}$ are the farmer's expected profits with and without the yield uncertainty insurance, respectively. According to the analysis in the last section, we can easily get

$$
\triangle \pi_{f}= \begin{cases}\frac{\pi_{f}^{*}-\pi_{f}^{N *}}{\pi_{f}^{N *}}, & \text { if } \eta_{0} \leq \eta<1, \\ 0, & \text { if } 0<\eta<\eta_{0} .\end{cases}
$$

Therefore, we only need to consider the case that $\eta_{0} \leq \eta<1$.

Unfortunately, it turns out that the value of yield insurance does not have a clear monotonic relationship with the risk aversion level, financing interest rate, yield volatility variances and premium subsidy rates. Thus we use some numerical examples to illustrate the relations (see Fig. 6).

Figure 6a illustrates effects of the risk aversion level $\eta$ on the yield insurance value $\Delta \pi_{f}$ for different premium subsidy rate $h$. First, we can see that the impact of the yield insurance is not always positive, and it depends on the value of the premium subsidy rate $h$. More about the effects of $h$ can be seen in Figure $6 \mathrm{~d}$ and the discussion 


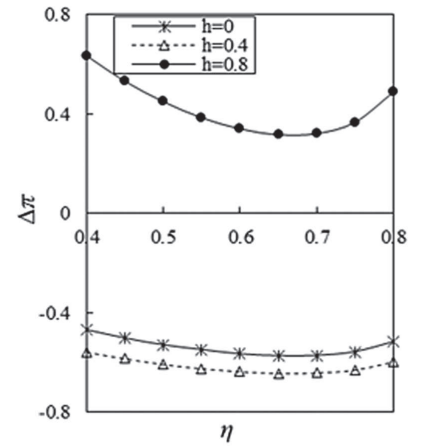

(a)

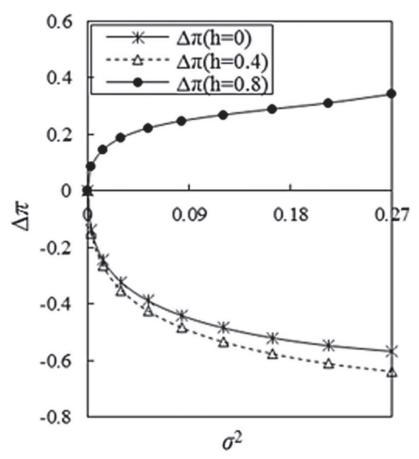

(c)

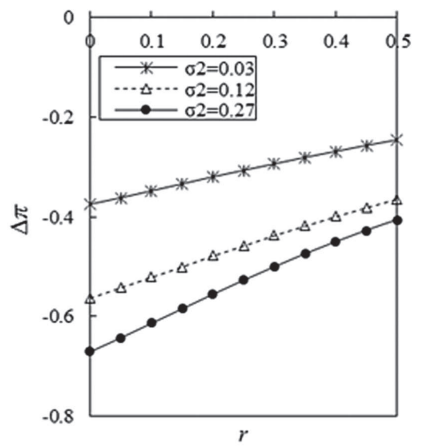

(b)

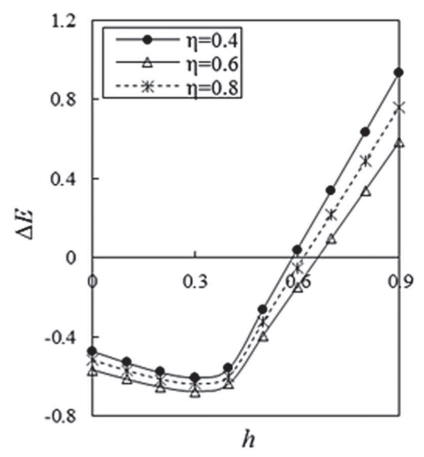

(d)

Figure 6. Effects of $\eta, r, \sigma^{2}$ and $h$ on the yield insurance value.

below. Now we focus on the impacts of the risk aversion level $\eta$. From Figure $6 \mathrm{a}$, We can see that $\Delta \pi_{f}$ first decreases then increases with respect to $\eta$. This is because without the yield insurance, although the total yield decreases with the risk aversion, the wholesale price $w^{*}$ increases accordingly, which can offset the decrease of the farmers' profits. However, the wholesale price $w^{*}$ will be lower for farmers with the yield insurance. Therefore, the impact of the yield insurance is not monotonic with respect to the farmer's risk aversion level $\eta$.

Figure $6 \mathrm{~b}$ shows that the yield insurance value increases with the financing rate $r$ for different yield volatility variances $\left(\sigma^{2}=0.03,0.12,0.27\right)$. From the figure, we can see that the yield insurance can effectively alleviate the problem of expensive financing for the capital constrained farmer. This is because that, with insurance, the farmer's yield uncertainty risk is borne by the insurance company. The managerial insight is that the government and the bank should encourage or subsidize the farmer who borrows bank loans to purchase yield insurance.

Figure $6 \mathrm{c}$ indicates that the yield insurance value $\Delta \pi_{f}$ increases with respect to the yield uncertainty level $\sigma^{2}$ when the premium subsidy rate $h$ is relatively high $(h=0.8)$, and decreases with respect to $\sigma^{2}$ when $h$ is low $(h=0,0.4)$. The managerial insight is that the government should provide an adequate level of premium subsidy and regulate the wholesale price of the agricultural products to protect farmers' interests.

From Figure $6 \mathrm{~d}$, we can see that $\Delta \pi_{f}$ first decreases then increases with respect to $h$ for different risk aversion $(\eta=0.4,0.6,0.8)$. In addition, the impact of the yield insurance becomes positive only if the premium subsidy rate $h$ is sufficiently large, and it also depends of the farmer's risk aversion level $\eta$. This is because the wholesale price $w^{*}$ of the agricultural products decreases with respect to the premium subsidy rate $h$ (see Prop. 5.4) and is lower than that without insurance (see Prop. 5.5). So, when the subsidy rate is relatively low, the farmer's profit will decrease with respect to $h$ because of the lower wholesale price $w^{*}$. The management implication is that when the premium subsidy rate is relatively low, in order to protect the farmer's interest, it becomes more important to regulate the wholesale price of the agricultural products. 
In addition, from Figure 6, we can also see that the value of yield insurance to farmers is not always positive, which mainly depends on the premium subsidy rate $h$. When the premium subsidy rate $h$ is relatively high, the farmer's expected profit under the yield insurance is higher than that without insurance. However, the farmer's expected profit under the yield insurance is lower than that without insurance when $h$ is low. This may be partly due to the fact that farmers usually have no pricing power in the contract-farming supply chain, and the benefit of the yield insurance to farmers is not enough to offset the decline in farmers' profit caused by the lower wholesale price when the premium subsidy rate is low. The managerial insight is that when developing countries cannot provide higher premium subsidies due to limited financial resources, the government can also increase the value of agricultural insurance by increasing the farmers' bargaining power by forming agricultural cooperatives or regulate the wholesale price of agricultural products.

\section{Conclusions}

In this paper, we consider a two-level contract-farming supply chain including a risk-averse farmer and a risk-neutral agro-dealer, where the farmer faces yield uncertainty and capital constraints. Under the yield insurance mechanism, we construct the Stackelberg game model to study the farmer's optimal production decision, insurance decision and the agro-dealer's optimal wholesale decision. The results show that farmers with low risk aversion will not be insured, while those with high risk aversion will choose to insure. In addition, as the farmer's risk aversion increases, the farm size decrease, but the yield per unit area and the wholesale price of agricultural products increases. The agricultural insurance mechanism effectively solves the adverse effects of the farmer's risk aversion, and increases the farmer's farm size, total yield and consumer welfare. However, the level of farmer's efforts (yield per unit area) and the wholesale price of agricultural products will decline, which will reduce the effect of agricultural insurance and premium subsidies. The results also show that as the risk of yield uncertainty and financing costs increases, the farm size and the total yield decreases. Therefore, yield uncertainty adversely affects the profits of the farmer and agro-dealer, but the farmer increases the yield per unit area by increasing the level of effort. By analyzing the value of yield insurance, we show that the value of yield insurance to farmers is not always positive, and it mainly depends on the premium subsidy rate. Moreover, the value of yield insurance increases with the bank's interest rate.

There are still some limitations in our work. For example, to simplify our model, we only consider an agrodealer and a farmer. However, in actual situations, an agro-dealer often faces multiple farmers. Therefore, research on the optimal strategies for a contract-farming supply chain consisting of an agro-dealer and multiple farmers will be interesting under yield insurance and premium subsidies.

\section{Appendix A.}

\section{A.1. Proof of Proposition 4.1}

We assume that the decision order of the farmer is that, he/she chooses a optimal guarantee level of yield insurance first, and then he/she chooses the optimal production strategies. We solve the problem backward.

(1) We first discuss the optimal production strategies of the risk-averse farmer. Let

$$
g(s, q, v)=v+\frac{1}{1-\eta} E\left[\min \left(\pi_{f}(s, q)-v, 0\right)\right] .
$$

Therefore, the farmer's optimal production decision is

$$
\max _{s, q}\left\{\mathrm{CVaR}_{1-\eta}\left(\pi_{f}(s, q)\right)\right\}=\max _{s, q}\left\{\max _{v} g(s, q, v)\right\} .
$$


By substituting (4.1) into (A.1), we have

$$
\begin{aligned}
g(s, q, v)= & v-\frac{1}{1-\eta} E[v-w s q \max (X, \mu)+(1+r)(C(s, q)+(1-h) \lambda)-r \zeta]^{+}, \\
= & \left\{\begin{array}{cc}
v, & v<v_{1} ; \\
v-\frac{1}{1-\eta} \int_{0}^{\mu}[v-w s q \mu+(1+r)(C(s, q)+(1-h) \lambda)-r \zeta] f(x) \mathrm{d} x & \\
-\frac{1}{1-\eta} \int_{\mu}^{A}[v-w s q X+(1+r)(C(s, q)+(1-h) \lambda)-r \zeta] f(x) \mathrm{d} x, v_{1} \leq v<v_{2} \\
v-\frac{1}{1-\eta} \int_{0}^{\mu}[v-w s q \mu+(1+r)(C(s, q)+(1-h) \lambda)-r \zeta] f(x) \mathrm{d} x \\
-\frac{1}{1-\eta} \int_{\mu}^{\beta}[v-w s q X+(1+r)(C(s, q)+(1-h) \lambda)-r \zeta] f(x) \mathrm{d} x, v \geq v_{2} .
\end{array}\right.
\end{aligned}
$$

where $v_{1}=w s q \mu-(1+r)[C(s, q)+(1-h) \lambda]+r \zeta, v_{2}=w s q \beta-(1+r)[C(s, q)+(1-h) \lambda]+r \zeta, A=$ $\frac{v+(1+r)[C(s, q)+(1-h) \lambda]-r \zeta}{w s q}$. So, we can get that

$$
\frac{\partial g(s, q, v)}{\partial v}= \begin{cases}1>0, & v<v_{1} \\ 1-\frac{1}{1-\eta} F(A), & v_{1} \leq v<v_{2} \\ 1-\frac{1}{1-\eta}<0, & v \geq v_{2}\end{cases}
$$

We can see that when $v_{1} \leq v<v_{2}$,

$$
\left.\frac{\partial g(s, q, v)}{\partial v}\right|_{v=v_{1}^{+}}=1-\frac{1}{1-\eta} F(\mu),\left.\quad \frac{\partial g(s, q, v)}{\partial v}\right|_{v=v_{2}^{-}}=1-\frac{1}{1-\eta}<0 .
$$

So, when $0 \leq \mu \leq F^{-1}(1-\eta), 1-\frac{1}{1-\eta} F(\mu) \geq 0$, the optimal value $v^{*}$ is in $\left(v_{1}, v_{2}\right)$. Let $\frac{\partial g(s, q, v)}{\partial v}=$ $1-\frac{1}{1-\eta} F(A)=0$, we can get that $v^{*}=w s q F^{-1}(1-\eta)-(1+r)[C(s, q)+(1-h) \lambda]+r \zeta$. Otherwise, when $F^{-1}(1-\eta)<\mu \leq \beta, 1-\frac{1}{1-\eta} F(\mu)<0$, then $v^{*}=v_{1}$. Therefore, we have

$$
v^{*}= \begin{cases}w s q F^{-1}(1-\eta)-(1+r)[C(s, q)+(1-h) \lambda]+r \zeta, & 0 \leq \mu \leq F^{-1}(1-\eta) \\ w s q \mu-(1+r)[C(s, q)+(1-h) \lambda]+r \zeta, & F^{-1}(1-\eta)<\mu \leq \beta\end{cases}
$$

Plugging (A.3) into (A.2), we can get that

$$
g\left(s, q, v^{*}\right)=\left\{\begin{array}{cl}
\frac{1}{1-\eta} w s q\left[\int_{\mu}^{F^{-1}(1-\eta)} x f(x) \mathrm{d} x+\mu F(\mu)\right], & \\
-(1+r)[C(s, q)+(1-h) \lambda]+r \zeta, & 0 \leq \mu \leq F^{-1}(1-\eta) ; \\
w s q \mu-(1+r)[C(s, q)+(1-h) \lambda]+r \zeta, & F^{-1}(1-\eta)<\mu \leq \beta .
\end{array}\right.
$$

When $0 \leq \mu \leq F^{-1}(1-\eta)$, we have $\frac{\partial g\left(s, q, v^{*}\right)}{\partial s}=\frac{w q}{1-\eta}\left[\int_{\mu}^{F^{-1}(1-\eta)} x f(x) \mathrm{d} x+\mu F(\mu)\right]-$ $(1+r)\left[c_{1}+2 c_{2}\left(s-s_{0}\right)+2 c_{3} s\left(q-q_{0}\right)^{2}+(1-h)(1+\theta) w q \int_{0}^{\mu} F(x) \mathrm{d} x\right], \quad \frac{\partial g\left(s, q, v^{*}\right)}{\partial q} \quad=$ $\frac{w s}{1-\eta}\left[\int_{\mu}^{F^{-1}(1-\eta)} x f(x) \mathrm{d} x+\mu F(\mu)\right]-(1+r) s\left[2 c_{3} s\left(q-q_{0}\right)+(1-h)(1+\theta) w \int_{0}^{\mu} F(x) \mathrm{d} x\right], \quad \frac{\partial^{2} g\left(s, q, v^{*}\right)}{\partial q^{2}}=$ $-2(1+r) c_{3} s^{2}, \frac{\partial^{2} g\left(s, q, v^{*}\right)}{\partial s^{2}}=-(1+r)\left[2 c_{2}+2 c_{3}\left(q-q_{0}\right)^{2}\right], \frac{\partial^{2} g\left(s, q, v^{*}\right)}{\partial s \partial q}=-2 c_{3} s(1+r)\left(q-q_{0}\right)$. Therefore,

$$
\frac{\partial^{2} g\left(s, q, v^{*}\right)}{\partial s^{2}}<0,\left|\begin{array}{ll}
\frac{\partial^{2} g\left(s, q, v^{*}\right)}{\partial s^{2}} & \frac{\partial^{2} g\left(s, q, v^{*}\right)}{\partial s \partial q} \\
\frac{\partial^{2} g\left(s, q, v^{*}\right)}{\partial s \partial q} & \frac{\partial^{2} g\left(s, q, v^{*}\right)}{\partial q^{2}}
\end{array}\right|=4(1+r)^{2} c_{2} c_{3} s^{2}>0 .
$$

So, the Hessian is negative definite. Let $\frac{\partial g\left(s, q, v^{*}\right)}{\partial s}=0, \frac{\partial g\left(s, q, v^{*}\right)}{\partial q}=0$, we can get that

$$
\left\{\begin{array}{l}
s^{*}=s_{0}+\frac{w q_{0}\left(\frac{1}{1-\eta}\left[\int_{\mu}^{F^{-1}(1-\eta)} x f(x) \mathrm{d} x+\mu F(\mu)\right]-(1+r)(1-h)(1+\theta) \int_{0}^{\mu} F(x) \mathrm{d} x\right)}{2 c_{2}(1+r)}-\frac{c_{1}}{2 c_{2}}, \\
q^{*}=q_{0}+\frac{w\left(\frac{1}{1-\eta}\left[\int_{\mu}^{F^{-1}(1-\eta)} x f(x) \mathrm{d} x+\mu F(\mu)\right]-(1+r)(1-h)(1+\theta) \int_{0}^{\mu} F(x) \mathrm{d} x\right)}{2 c_{3}(1+r) s^{*}} .
\end{array}\right.
$$


When $F^{-1}(1-\eta)<\mu \leq \beta$, we have $\frac{\partial g\left(s, q, v^{*}\right)}{\partial s}=w q \mu-(1+r)\left[c_{1}+2 c_{2}\left(s-s_{0}\right)+2 c_{3} s\left(q-q_{0}\right)^{2}+(1-\right.$ $\left.h)(1+\beta) w q \int_{0}^{\mu} F(x) \mathrm{d} x\right], \frac{\partial g\left(s, q, v^{*}\right)}{\partial q}=w s \mu-(1+r) s\left[2 c_{3} s\left(q-q_{0}\right)+(1-h)(1+\beta) w \int_{0}^{\mu} F(x) \mathrm{d} x\right], \frac{\partial^{2} g\left(s, q, v^{*}\right)}{\partial s^{2}}=$ $-2(1+r)\left[c_{2}+c_{3}\left(q-q_{0}\right)^{2}\right], \frac{\partial^{2} g\left(s, q, v^{*}\right)}{\partial q^{2}}=-2(1+r) c_{3} s^{2}, \frac{\partial^{2} g\left(s, q, v^{*}\right)}{\partial s \partial q}=-2 c_{3} s(1+r)\left(q-q_{0}\right)$. Therefore,

$$
\frac{\partial^{2} g\left(s, q, v^{*}\right)}{\partial s^{2}}<0,\left|\begin{array}{ll}
\frac{\partial^{2} g\left(s, q, v^{*}\right)}{\partial s^{2}} & \frac{\partial^{2} g\left(s, q, v^{*}\right)}{\partial s \partial q} \\
\frac{\partial^{2} g\left(s, q, v^{*}\right)}{\partial s \partial q} & \frac{\partial^{2} g\left(s, q, v^{*}\right)}{\partial q^{2}}
\end{array}\right|=4(1+r)^{2} c_{2} c_{3} s^{2}>0 .
$$

So, the Hessian is negative definite. Let $\frac{\partial g\left(s, q, v^{*}\right)}{\partial s}=0, \frac{\partial g\left(s, q, v^{*}\right)}{\partial q}=0$, we can get that

$$
\left\{\begin{array}{l}
s^{*}=s_{0}+\frac{w q_{0}\left[\mu-(1+r)(1-h)(1+\theta) \int_{0}^{\mu} F(x) \mathrm{d} x\right]}{2 c_{2}(1+r)}-\frac{c_{1}}{2 c_{2}}, \\
q^{*}=q_{0}+\frac{w\left[\mu-(1+r)(1-h)(1+\theta) \int_{0}^{\mu} F(x) \mathrm{d} x\right]}{2 c_{3}(1+r) s^{*}}
\end{array}\right.
$$

(2) We now discuss the optimal insurance decision of the risk-averse farmer under the CVaR criterion. By virtue of (A.4)-(A.6), we can get that

$$
\frac{\partial g\left(s^{*}, q^{*}, \mu\right)}{\partial \mu}= \begin{cases}{\left[\frac{1}{1-\eta}-(1+r)(1-h)(1+\theta)\right] w Q^{*} F(\mu),} & 0 \leq \mu \leq F^{-1}(1-\eta) \\ {[1-(1+r)(1-h)(1+\theta) F(\mu)] w Q^{*},} & F^{-1}(1-\eta)<\mu \leq \beta .\end{cases}
$$

When $(1+r)(1-h)(1+\theta)>\frac{1}{1-\eta}$, i.e., $0<\eta<1-\frac{1}{(1+r)(1-h)(1+\theta)}$, we can see that for any $\mu \in[0, \beta], \frac{d g\left(s^{*}, q^{*}, \mu\right)}{d \mu}<0$, so $\mu^{*}=0$.

Next, we will consider the condition that $(1+r)(1-h)(1+\theta) \leq \frac{1}{1-\eta}$, i.e., $1-\frac{1}{(1+r)(1-h)(1+\theta)} \leq \eta<1$. Under this condition, $\frac{d g\left(s^{*}, q^{*}, \mu\right)}{d \mu}>0$ when $0 \leq \mu \leq F^{-1}(1-\eta)$. And when $F^{-1}(1-\eta)<\mu \leq \beta$, set $\frac{\partial g\left(s^{*}, q^{*}, \mu\right)}{\partial \mu}=0$, we can get $\mu^{*}=F^{-1}\left(\frac{1}{(1+r)(1-h)(1+\theta)}\right)$ and $\left.\frac{\partial^{2} g\left(s^{*}, q^{*}, \mu\right)}{\partial \mu^{2}}\right|_{\mu=\mu^{*}}=-(1+r)(1-h)(1+\theta) f(\mu) w Q^{*}<0$. So, $\mu^{*}=F^{-1}\left(\frac{1}{(1+r)(1-h)(1+\theta)}\right)$ is the maximum point of $g\left(s^{*}, q^{*}, \mu\right)$ under this condition.

Therefore, the optimal yield guarantee level of the risk-averse farmer satisfies

$$
\mu^{*}=\left\{\begin{array}{ll}
F^{-1}\left(\frac{1}{(1+r)(1-h)(1+\theta)}\right), & 1-\frac{1}{(1+r)(1-h)(1+\theta)} \leq \eta<1 \\
0, & 0<\eta<1-\frac{1}{(1+r)(1-h)(1+\theta)}
\end{array} .\right.
$$

Virtue of (A.7) into (A.5) and (A.6), we can get (4.3).

\section{A.2. Proof of Proposition 4.2}

From (4.3), we can get that

$$
\begin{aligned}
& \frac{\mathrm{d} s^{*}}{\mathrm{~d} w}= \begin{cases}\frac{q_{0} G\left(1-\eta_{0}\right)}{2 c_{2}(1+r)}>0, & \eta_{0} \leq \eta<1 ; \\
\frac{q_{0} G(1-\eta)}{2 c_{2}(1-\eta)(1+r)}>0, & 0<\eta<\eta_{0} .\end{cases} \\
& \frac{\mathrm{d} Q^{*}}{\mathrm{~d} w}= \begin{cases}\frac{\left(c_{2}+c_{3} q_{0}^{2}\right) G\left(1-\eta_{0}\right)}{2 c_{2} c_{3}(1+r)}>0, & \eta_{0} \leq \eta<1 ; \\
\frac{\left(c_{2}+c_{3} q_{0}^{2}\right) G(1-\eta)}{2 c_{2} c_{3}(1-\eta)(1+r)}>0 . & 0<\eta<\eta_{0} .\end{cases}
\end{aligned}
$$




\section{A.3. Proof of Proposition 4.3}

From (4.6), we can get that

$$
\begin{aligned}
\frac{\mathrm{d} \pi_{m}(w)}{\mathrm{d} w} & =\frac{\partial \pi_{m}(w)}{\partial w}+\frac{\partial \pi_{m}(w)}{\partial Q^{*}} \cdot \frac{\mathrm{d} Q^{*}}{\mathrm{~d} w} \\
& =-Q^{*}+\left[a-w-2 b Q^{*}\left(1+\sigma^{2}\right)\right] B, \\
\frac{\mathrm{d}^{2} \pi_{m}(w)}{\mathrm{d} w^{2}} & =-2 B\left[1+b\left(1+\sigma^{2}\right) B\right]<0 .
\end{aligned}
$$

Thus, $\pi_{m}(w)$ is a concave function of $w$, Let $\frac{\mathrm{d} \pi_{m}}{\mathrm{~d} w}=0$, we can get $w^{*}$.

\section{A.4. Proof of Lemma 5.1}

From (4.9), we can get that

$$
\begin{aligned}
& \frac{\mathrm{d} B}{\mathrm{~d} r}= \begin{cases}-\frac{\left(c_{2}+c_{3} q_{0}^{2}\right) F^{-1}\left(1-\eta_{0}\right)}{2 c_{2} c_{3}(1+r)^{2}}<0, & \eta_{0} \leq \eta<1 ; \\
-\frac{\left(c_{2}+c_{3} q_{0}^{2}\right) G(1-\eta)}{2 c_{2} c_{3}(1-\eta)(1+r)^{2}}<0, & 0<\eta<\eta_{0} ;\end{cases} \\
& \frac{\mathrm{d} B}{\mathrm{~d} \eta}= \begin{cases}0, & \eta_{0} \leq \eta<1 ; \\
-\frac{\left(c_{2}+c_{3} q_{0}^{2}\right) \int_{0}^{F^{-1}(1-\eta)} F(x) \mathrm{d} x}{2 c_{2} c_{3}(1-\eta)^{2}(1+r)}<0, & 0<\eta<\eta_{0} ;\end{cases} \\
& \frac{\mathrm{d} B}{\mathrm{~d} h}= \begin{cases}\frac{\left(c_{2}+c_{3} q_{0}^{2}\right)(1+\theta) \int_{0}^{F^{-1}\left(1-\eta_{0}\right)} F(x) \mathrm{d} x}{2 c_{2} c_{3}}>0, & \eta_{0} \leq \eta<1 ; \\
0, & 0<\eta<\eta_{0} ;\end{cases} \\
& \frac{\mathrm{d} B}{\mathrm{~d} \theta}= \begin{cases}-\frac{\left(c_{2}+c_{3} q_{0}^{2}\right)(1-h) \int_{0}^{F^{-1}\left(1-\eta_{0}\right)} F(x) \mathrm{d} x}{2 c_{2} c_{3}}<0, & \eta_{0} \leq \eta<1 ; \\
0, & 0<\eta<\eta_{0} .\end{cases}
\end{aligned}
$$

\section{A.5. Proof of Proposition 5.2}

(1) From (4.10), it is easy to get that

$$
s^{*}=s_{0}+\frac{2 c_{2} c_{3} B a q_{0}-c_{1} c_{3} q_{0}^{2}}{4 c_{2}\left(c_{2}+c_{3} q_{0}^{2}\right)\left[1+B b\left(1+\sigma^{2}\right)\right]}-\frac{c_{1}}{2\left(c_{2}+c_{3} q_{0}^{2}\right)} .
$$

According to (A.8), we have $\frac{d s^{*}}{d \sigma^{2}}<0$. Meanwhile, we can get that

$$
s^{*}=s_{0}+\frac{2 c_{2} c_{3} a q_{0}-c_{1} c_{3} q_{0}^{2}}{4 c_{2}\left(c_{2}+c_{3} q_{0}^{2}\right)\left[\frac{1}{B}+b\left(1+\sigma^{2}\right)\right]}-\frac{c_{1} c_{3} q_{0}^{2}}{4 c_{2}\left(c_{2}+c_{3} q_{0}^{2}\right)\left[1+B b\left(1+\sigma^{2}\right)\right]}-\frac{c_{1}}{2\left(c_{2}+c_{3} q_{0}^{2}\right)} .
$$

So, we have $\frac{\mathrm{d} s^{*}}{\mathrm{~d} B}>0$. Then, according to Lemma 5.1, we have

$$
\begin{aligned}
& \frac{\mathrm{d} s^{*}}{\mathrm{~d} r}=\frac{\mathrm{d} s^{*}}{\mathrm{~d} B} \frac{\mathrm{d} B}{\mathrm{~d} r}<0 ; \quad \frac{\mathrm{d} s^{*}}{\mathrm{~d} h}= \begin{cases}\frac{\mathrm{d} s^{*}}{\mathrm{~d} B} \frac{\mathrm{d} B}{\mathrm{~d} h}>0, & \eta_{0} \leq \eta<1 ; \\
0, & 0<\eta<\eta_{0}\end{cases} \\
& \frac{\mathrm{d} s^{*}}{\mathrm{~d} \theta}=\left\{\begin{array}{ll}
\frac{\mathrm{d} s^{*}}{\mathrm{~d} B} \frac{\mathrm{d} B}{\mathrm{~d} \theta}<0, & \eta_{0} \leq \eta<1 ; \\
0, & 0<\eta<\eta_{0} ;
\end{array} \quad \frac{\mathrm{d} s^{*}}{\mathrm{~d} \eta}= \begin{cases}0, & \eta_{0} \leq \eta<1 ; \\
\frac{\mathrm{d} s^{*}}{\mathrm{~d} B} \frac{\mathrm{d} B}{\mathrm{~d} \eta}<0, & 0<\eta<\eta_{0} .\end{cases} \right.
\end{aligned}
$$

(2) From (4.10), it is easy to get that $\frac{\mathrm{d} q^{*}}{\mathrm{~d} \sigma^{2}}>0$. Then, from (4.10), we can get that

$$
q^{*}=q_{0}+\frac{2 c_{2}^{2} a+c_{1} c_{2} q_{0}\left[\frac{1}{B}+2 b\left(1+\sigma^{2}\right)\right]}{2 c_{2} c_{3} a q_{0}-c_{1}\left[\left(2 c_{2}+c_{3} q_{0}^{2}\right) \frac{1}{B}+2 c_{2} b\left(1+\sigma^{2}\right)\right]} .
$$


So, we have $\frac{\mathrm{d} q^{*}}{\mathrm{~d} B}<0$. Then, according to Lemma 5.1, we have

$$
\begin{aligned}
& \frac{\mathrm{d} q^{*}}{\mathrm{~d} r}=\frac{\mathrm{d} q^{*}}{\mathrm{~d} B} \frac{\mathrm{d} B}{\mathrm{~d} r}>0 ; \quad \frac{\mathrm{d} q^{*}}{\mathrm{~d} h}= \begin{cases}\frac{\mathrm{d} q^{*}}{\mathrm{~d} B} \frac{\mathrm{d} B}{\mathrm{~d} h}<0, & \eta_{0} \leq \eta<1 ; \\
0, & 0<\eta<\eta_{0}\end{cases} \\
& \frac{\mathrm{d} q^{*}}{\mathrm{~d} \theta}=\left\{\begin{array}{ll}
\frac{\mathrm{d} q^{*}}{\mathrm{~d} B} \frac{\mathrm{d} B}{\mathrm{~d} \theta}>0, & \eta_{0} \leq \eta<1 ; \\
0, & 0<\eta<\eta_{0} ;
\end{array} \quad \frac{\mathrm{d} q^{*}}{\mathrm{~d} \eta}= \begin{cases}0, & \eta_{0} \leq \eta<1 ; \\
\frac{\mathrm{d} q^{*}}{\mathrm{~d} B} \frac{\mathrm{d} B}{\mathrm{~d} \eta}>0, & 0<\eta<\eta_{0} .\end{cases} \right.
\end{aligned}
$$

(3) From (4.8), we can get that

$$
Q^{*}=s^{*} q^{*}=\frac{a-w}{\frac{1}{B}+2 b\left(1+\sigma^{2}\right)} .
$$

From (4.10), we have $\frac{\mathrm{d} w^{*}}{\mathrm{~d} B}<0$. Then, by virtue of Lemma 5.1 , we have

$$
\begin{aligned}
& \frac{\mathrm{d} w^{*}}{\mathrm{~d} r}>0, \quad \frac{\mathrm{d} w^{*}}{\mathrm{~d} h}= \begin{cases}\frac{\mathrm{d} w^{*}}{\mathrm{~d} B} \frac{\mathrm{d} B}{\mathrm{~d} h}<0, & \eta_{0} \leq \eta<1 \\
0, & 0<\eta<\eta_{0}\end{cases}
\end{aligned}
$$

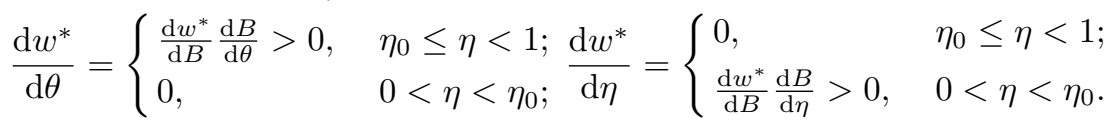

Therefore, we can get that

$$
\frac{\mathrm{d} Q^{*}}{\mathrm{~d} r}>0 ; \quad\left\{\begin{array} { l l } 
{ \frac { \mathrm { d } Q ^ { * } } { \mathrm { d } h } > 0 , } & { \eta _ { 0 } \leq \eta < 1 ; } \\
{ \frac { \mathrm { d } Q ^ { * } } { \mathrm { d } h } = 0 , } & { 0 < \eta < \eta _ { 0 } ; }
\end{array} \left\{\begin{array}{ll}
\frac{\mathrm{d} Q^{*}}{\mathrm{~d} \theta}<0, & \eta_{0} \leq \eta<1 ; \\
\frac{\mathrm{d} Q^{*}}{\mathrm{~d} \theta}=0, & 0<\eta<\eta_{0}
\end{array} ; \begin{cases}\frac{\mathrm{d} Q^{*}}{\mathrm{~d} \eta}=0, & \eta_{0} \leq \eta<1 \\
\frac{\mathrm{d} Q^{*}}{\mathrm{~d} \eta}<0, & 0<\eta<\eta_{0}\end{cases}\right.\right.
$$

\section{A.6. Proof of Proposition 5.3}

(1) Noting that $\eta_{0}=1-\frac{1}{(1+r)(1-h)(1+\theta)}$, we can get

$$
\frac{\mathrm{d} \eta_{0}}{\mathrm{~d} r}=\frac{1}{(1-h)(1+\theta)(1+r)^{2}}>0, \frac{\mathrm{d} \eta_{0}}{\mathrm{~d} h}=-\frac{1}{(1+r)(1-h)^{2}(1+\theta)}<0, \frac{\mathrm{d} \eta_{0}}{\mathrm{~d} \theta}=\frac{1}{(1+r)(1-h)(1+\theta)^{2}}>0 .
$$

(2) From (4.3), we can see that when the farmer chooses to insure, the yield guarantee level $\mu^{*}$ is

$$
\mu^{*}=F^{-1}\left(\frac{1}{(1+r)(1-h)(1+\theta)}\right) .
$$

Therefore, we have

$$
\begin{aligned}
& \frac{\mathrm{d} \mu^{*}}{\mathrm{~d} r}=-\frac{1}{(1+r)^{2}(1-h)(1+\theta) f\left(\mu^{*}\right)}<0, \quad \frac{\mathrm{d} \mu^{*}}{\mathrm{~d} h}=\frac{1}{(1+r)(1-h)^{2}(1+\theta) f\left(\mu^{*}\right)}>0, \\
& \frac{\mathrm{d} \mu^{*}}{\mathrm{~d} \eta}=0, \quad \frac{\mathrm{d} \mu^{*}}{\mathrm{~d} \theta}=-\frac{1}{(1+r)(1-h)(1+\theta)^{2} f\left(\mu^{*}\right)}>0 .
\end{aligned}
$$

\section{A.7. Proof of Proposition 5.4}

(1) In fact, we've got the following results in the proof of Proposition 5.2:

$$
\frac{\mathrm{d} w^{*}}{\mathrm{~d} r}>0 ; \quad\left\{\begin{array} { l l } 
{ \frac { \mathrm { d } w ^ { * } } { \mathrm { d } h } < 0 , } & { \eta _ { 0 } \leq \eta < 1 ; } \\
{ \frac { \mathrm { d } w ^ { * } } { \mathrm { d } h } = 0 , } & { 0 < \eta < \eta _ { 0 } ; }
\end{array} \left\{\begin{array}{ll}
\frac{\mathrm{d} w^{*}}{\mathrm{~d} \theta}>0, & \eta_{0} \leq \eta<1 ; \\
\frac{\mathrm{d} w^{*}}{\mathrm{~d} \theta}=0, & 0<\eta<\eta_{0}
\end{array} ; \begin{cases}\frac{\mathrm{d} w^{*}}{\mathrm{~d} \eta}=0, & \eta_{0} \leq \eta<1 \\
\frac{\mathrm{d} w^{*}}{\mathrm{~d} \eta}>0, & 0<\eta<\eta_{0}\end{cases}\right.\right.
$$


(2) By virtue of (A.9), we have

$$
\frac{Q^{*}}{B}=a-w^{*}-2 b Q^{*}\left(1+\sigma^{2}\right) .
$$

Therefore, by virtue of Proposition 5.2, we can get that

$$
\frac{\mathrm{d} \pi_{m}}{\mathrm{~d} r}<0 ; \quad\left\{\begin{array} { l l } 
{ \frac { \mathrm { d } \pi _ { m } } { \mathrm { d } h } > 0 , } & { \eta _ { 0 } \leq \eta < 1 ; } \\
{ \frac { \mathrm { d } \pi _ { m } } { \mathrm { d } h } = 0 , } & { 0 < \eta < \eta _ { 0 } ; }
\end{array} \left\{\begin{array}{ll}
\frac{\mathrm{d} \pi_{m}}{\mathrm{~d} \theta}<0, & \eta_{0} \leq \eta<1 ; \\
\frac{\mathrm{d} \pi_{m}}{\mathrm{~d} \theta}=0, & 0<\eta<\eta_{0}
\end{array} ; \begin{cases}\frac{\mathrm{d} \pi_{m}}{\mathrm{~d} \eta}=0, & \eta_{0} \leq \eta<1 \\
\frac{\mathrm{d} \pi_{m}}{\mathrm{~d} \eta}<0, & 0<\eta<\eta_{0}\end{cases}\right.\right.
$$

\section{A.8. Proof of Proposition 5.5}

From (4.9) and (4.12), we can get that

$$
B-B_{1}= \begin{cases}\frac{\left(c_{2}+c_{3} q_{0}^{2}\right)\left[G\left(1-\eta_{0}\right)-G(1-\eta)\right]}{2 c_{2} c_{3}(1+r)}, & \eta_{0}<\eta<1 \\ 0, & 0<\eta \leq \eta_{0}\end{cases}
$$

Then, by virtue of $G(y)=F^{-1}(y)-\frac{1}{y} \int_{0}^{F^{-1}(y)} F(x) \mathrm{d} x$, we have

$$
\frac{\mathrm{d} G(y)}{\mathrm{d} y}=\frac{\int_{0}^{F^{-1}(y)} F(x) \mathrm{d} x}{y^{2}}>0 .
$$

So, when $\eta \geq \eta_{0}$, we have $G(1-\eta)<G\left(1-\eta_{0}\right), B>B_{1}$. Then, From (4.10) and (4.11), we can get that

$$
\left\{\begin{array}{ll}
s^{*}>s^{N *}, & \eta_{0}<\eta<1 ; \\
s^{*}=s^{N *}, & 0<\eta \leq \eta_{0}
\end{array} ;\left\{\begin{array}{ll}
q^{*}<q^{N *}, & \eta_{0}<\eta<1 ; \\
q^{*}=q^{N *}, & 0<\eta \leq \eta_{0}
\end{array} ; \begin{cases}w^{*}<w^{N *}, & \eta_{0}<\eta<1 ; \\
w^{*}=w^{N *}, & 0<\eta \leq \eta_{0} .\end{cases}\right.\right.
$$

Moreover, From (A.9), we can get that

$$
\begin{cases}Q^{*}>Q^{N *}, & \eta_{0}<\eta<1 \\ Q^{*}=Q^{N *}, & 0<\eta \leq \eta_{0}\end{cases}
$$

In addition, From (5.2), we can obtain that

$$
\begin{cases}\mathrm{CS}^{*}>\mathrm{CS}^{N *}, & \eta_{0}<\eta<1 ; \\ \mathrm{CS}^{*}=\mathrm{CS}^{N *}, & 0<\eta \leq \eta_{0} .\end{cases}
$$

Acknowledgements. The research is partially supported by the National Social Science Foundation of China (Grant No. 17BGL236) and Postgraduate Research \& Practice Innovation Program of Jiangsu Province (KYCX18_0975).

\section{REFERENCES}

[1] M. Agbo, D. Rousseliere and J. Salanie, Agricultural marketing cooperatives with direct selling: a cooperative non-cooperative game. J. Econ. Behav. Org. 109 (2015) 56-71.

[2] D. Ahmad, M. Afzal and A. Rauf, Analysis of wheat farmers' risk perceptions and attitudes: evidence from Punjab, Pakistan. Nat. Hazard. 95 (2019) 845-861.

[3] S. Alizamir, F. Iravani and F. Mamani, An analysis of price vs. revenue protection: government subsidies in the agriculture industry. Manage. Sci. 65 (2019) 32-49.

[4] E. Anderson and M. Monjardino, Contract design in agriculture supply chains with random yield. Eur. J. Oper. Res. 277 (2019) 1072-1082.

[5] K.B. Atici, A. Ulucan and I.U. Bayar, The measurement of agricultural productivity change in OECD countries with Fuzzy data. RAIRO:OR $\mathbf{5 2}$ (2018) 1003-1017. 
[6] P.J. Barry, K.J. Collins and J.W. Glauber, Crop insurance, disaster assistance, and the role of the federal government in providing catastrophic risk protection. Agric. Finance Rev. 62 (2013) 81-101.

[7] J.A. Buzacott and R.Q. Zhang, Inventory management with asset-based financing. Manage. Sci. 50 (2004) $1274-1292$.

[8] J. Cai, The impact of insurance provision on household production and financial decisions. Am. Econ. J.: Econ. Policy 8 (2016) 44-88.

[9] J.H. Cai, X.Q. Hu, F.Y. Jiang, Q. Zhou, X.Y. Zhang and L.Y. Xuan, Optimal input quantity decisions considering commitment order contracts under yield uncertainty. Int. J. Prod. Econ. 216 (2019) 398-412.

[10] X.F. Chen, A model of trade credit in a capital-constrained distribution channel. Int. J. Prod. Econ. 159 (2015) $347-357$.

[11] X. Chen, M. Sim, D. Simchi-Levi and P. Sun, Risk aversion in inventory management. Oper. Res. 55 (2007) 828-842.

[12] Y. Chen, M. Xu and G.A. Zhang, Risk-averse newsvendor model under the CVaR decision criterion. Oper. Res. 57 (2009) 1040-1044.

[13] K.Z. Chen, P.K. Joshi, E. Cheng and P.S. Birthal, Innovations in financing of agri-food value chains in China and India. Chin. Agric. Econ. Rev. 7 (2016) 616-640.

[14] J. Chen, H. Wei and L. Xie, The role of business insurance in managing a manufacturer's product quality risk. Oper. Res. Lett. 45 (2017) 635-641.

[15] B.B. Christopher, F.B. Marc and Y.H. Janet, Reconsidering conventional explanations of the inverse productivity-size relationship. Soc. Sci. Electron. Publ. 38 (2010) 88-97.

[16] S. Cole, D. Stein and J. Tobacman, Dynamics of demand for index insurance: evidence from a long-run field experiment. American Econ. Rev. 104 (2014) 284-290.

[17] CRSY, National agricultural products cost and profits. In Chapter 10 of China Rural Statistical Yearbook (2019) 273-279. https://data.cnki.net/area/yearbook/Single/N2019120190?z=D22.

[18] L.X. Dong and B. Tomlin, Managing disruption risk: the interplay between operations and insurance. Manage. Sci. 58 (2012) 1898-1915.

[19] X.D. Du, H.L. Feng and D.A. Hennessy, Rationality of choices in subsidized crop insurance markets. Am. J. Agric. Econ. 99 (2017) 732-756.

[20] E. Elahi, M. Abid, L. Zhang, S.U. Haq and J.G.M. Sahito, Agricultural advisory and financial services; farm level access, outreach and impact in a mixed cropping district of Punjab, Pakistan. Land Use Policy 71 (2018) 249-260.

[21] Z. Fadhliani, J. Luckstead and E.J. Wailes, The impacts of multiperil crop insurance on Indonesian rice farmers and production. Agri. Econ. 50 (2019) 15-26.

[22] FAO (Food and Agriculture Organization of the United Nations), 2017 The impact of disasters crises on agriculture and food security (2018). http://www.fao.org/3/I8656EN/i8656en.pdf.

[23] A. Federgruen, U. Lall and A.S. Simsek, Supply chain analysis of contract farming. Manuf. Serv. Oper. Manage. 21 (2019) $361-378$.

[24] H. Freudenreich and O. Musshoff, Insurance for technology adoption: an experimental evaluation of schemes and subsidies with Maize farmers in Mexico. J. Agric. Econ. 69 (2018) 96-120.

[25] H.Y. Fu, J.W. Li, Y.J. Li, S.Z. Huang and X.K. Sun, Risk transfer mechanism for agricultural products supply chain based on weather index insurance. Complexity 2018 (2018) 2369423.

[26] J.F. Gonzaga, O.F. Vilpoux and M.W.G. Pereira, Factors influencing influencing technological practices in the Brazilian agrarian reform. Land Use Policy 80 (2019) 150-162.

[27] J. He, X.Y. Zheng, R.M. Rejesus and J.M. Yorobe, Moral hazard and adverse selection effects of cost-of-production crop insurance: evidence from the Philippines. Aust. J. Agric. Res. Econ. 63 (2019) 166-197.

[28] A. Hervas, Land, development and contract farming on the Guatemalan oil palm frontier. J. Peasant Stud. 46 (2019) $115-141$.

[29] R.V. Hill, N. Kumar and N. Magnan, Ex ante and ex post effects of hybrid index insurance in Bangladesh. J. Dev. Econ. 136 (2019) 1-17.

[30] Y.S. Huang, Y.C. Hsu and H.H. Fang, A study on contractual agreements in supply chains of agricultural produce. Int. J. Prod. Res. 57 (2019) 3766-3783.

[31] X.L. Liu, Y.M. Tang, J.H. Ge and M.J. Miranda, Does experience with natural disasters affect willingness-to-pay for weather index insurance? Evidence from China. Int. J. Disaster Risk Reduction 33 (2019) 33-43.

[32] D. Luo, W.M. Li and J. Chen, Moderate scale of food production operations: two-dimensional perspective on output and efficiency. J. Manage. World 1 (2017) 78-88.

[33] T. Mieno, C.G. Walters and L.E. Fulginiti, Input use under crop insurance: the role of actual production history. Am. J. Agric. Econ. 100 (2018) 1469-1485.

[34] NAES (National Academy of Economic Strategy), 2016 Blue book on internet finance for agriculture, rural areas and farmers released by NAES, August 22, (2016). http://naes.cssn.cn/cj_zwz/zczx/zdgz/201608/t20160822_4283205.shtml.

[35] B. Niu, D. Jin and X. Pu, Coordination of channel members' efforts and utilities in contract farming operations. Eur. J. Oper. Res. 255 (2016) 869-883.

[36] C. Pantzios and P. Fousekis, Output price risk and productivity growth in greek agriculture. Spoudai 50 (2015) $106-124$.

[37] H.J. Peng and T. Pang, Financing strategies for a capital-constrained supplier under yield uncertainty. J. Ind. Manage. Optim. 16 (2020) 887-909.

[38] H.J. Peng and T. Pang, Optimal strategies for a three-level contract-farming supply chain with subsidy. Int. J. Prod. Econ. 216 (2019) 274-286. 
[39] J.C. Quiggin, G. Karagiannis and J. Stanton, Crop insurance and crop production: an empirical study of moral hazard and adverse selection. Aust. J. Agric. Econ. 37 (1993) 935-949.

[40] T.R. Rockafellar, Conditional value-at-risk for general loss distributions. J. Banking Finance 26 (2002) $1443-1471$.

[41] T.R. Rockafellar and S. Uryasev, Optimization of conditional value-at-risk. J. Risk 2 (2000) 21-42.

[42] A.K. Sharma, S. Tiwari, V. Yadavalli and C.K. Jaggi, Optimal trade credit and replenishment policies for non-instantaneous deteriorating items. RAIRO:OR 54 (2020) 1793-1826.

[43] G. Ton, W. Vellema and S. Desiere, Contract farming for improving smallholder incomes: What can we learn from effectiveness studies? World Dev. 104 (2018) 46-64.

[44] G.Z. Tuo, Rationality "insurance". J. Insurance Res. 9 (2007) 7-8+36.

[45] H.S. Vincent and K.G. Barry, Crop insurance, moral hazard, and agricultural chemical use. Am. J. Agric. Econ. 78 (1996) 428-438.

[46] W.L. Wang and N. Guo, Commercial insurance supports the operational decision of ordering the agricultural supply chain. Syst. Eng. 36 (2018) 85-95.

[47] D.D. Wu, L.P. Yang and D.L. Olson, Green supply chain management under capital constraint. Int. J. Prod. Econ. 215 (2018) $3-10$.

[48] B. Yan, Y.R. Chen and S.Y. He, Decision making and coordination of fresh agriculture product supply chain considering fairness concerns. RAIRO:OR 54 (2020) 1231-1248.

[49] H.L. Yang, L.L. Chu and H. Wan, Advertising and pricing policies in a two-echelon supply chain with a capital-constrained retailer. RAIRO:OR 53 (2019) 1331-1342.

[50] F. Ye, J.H. Huang and Q. Lin, The optimal production strategies of the farmer in contract-farming supply chain under capital constraint. Syst. Eng.-Theory Prac. 37 (2017) 1467-1478.

[51] F. Ye, Q. Lin and Y. Li, Coordination for contract farming supply chain with stochastic yield and demand under CVaR criterion. Oper. Res. 20 (2020) 369-397.

[52] X. Yu, W.G. Zhang and Y.J. Liu, Research on the subsidy mechanism of agricultural supply chain based on agricultural insurance. J. Manage. 14 (2017) 1546-1552.

[53] J.S. Yu, A. Smith and D.A. Sumner, Effects of crop insurance premium subsidies on crop acreage. Am. J. Agric. Econ. 100 (2018) 91-114.

[54] F. Zaura, The Impact of Crop Insurance on Indonesian Rice Production, Working Paper (2016).

[55] Z.R. Zhang, Agricultural insurance premiums constitution and government financial subsidies options. Finance Econ. 5 (2013) $18-25$.

[56] Y.W. Zhou, B. Cao, Y.G. Zhong and Y.Z. Wu, Optimal advertising/ordering policy and finance mode selection for a capitalconstrained retailer with stochastic demand. J. Oper. Res. Soc. 68 (2017) 1620-1632. 